
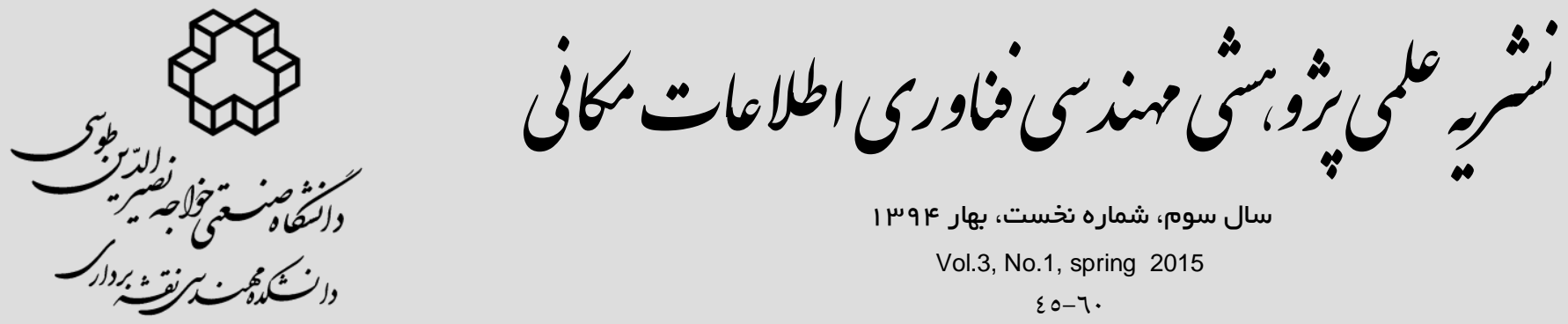

سال سوم، شماره نخست، بهار ع وس إ

Vol.3, No.1, spring 2015

乏०-ๆ.

تاثير انتخاب ويزگى به كمك الكوريتهم زنتيك بر طبقهبندى طيفى -مكانى تصاوير ابرطيفى

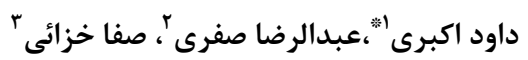

ا - دانشجوى دكترى سنجش از دور، دانشكده مهيندسى نقشه بردارى و اطلاعات مكانى، دانشكاه تهران

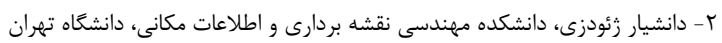

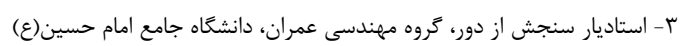

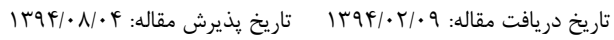

جكيده

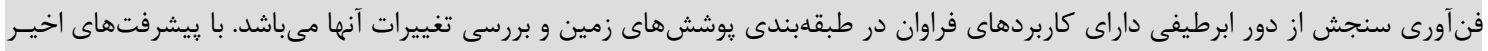

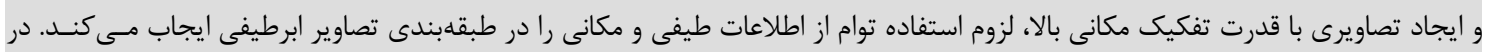

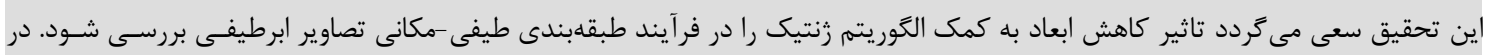

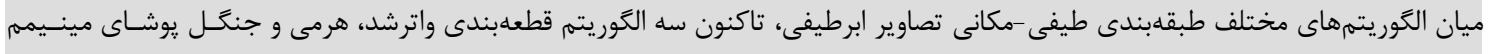

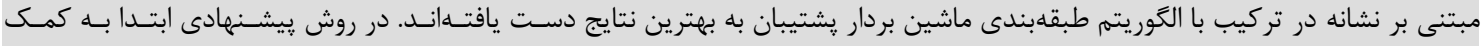

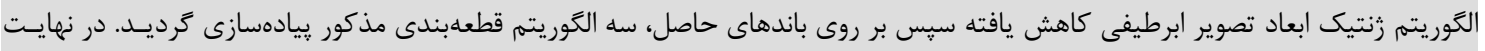

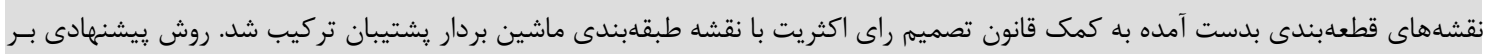

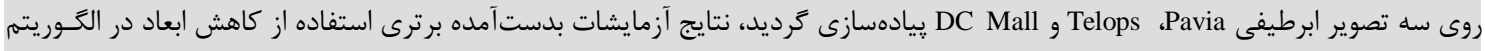

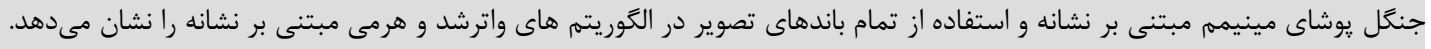

كليدوازهها: تصوير ابرطيفى، طبقدبندى طيفى-مكانى، كاهش ابعاد، الكوريته زنتيك.

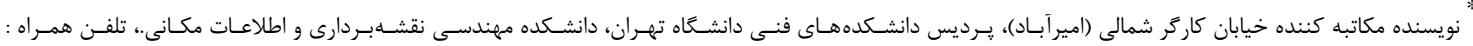

$.910 \Delta 919 \vee 99$

Email: davoodakbari@ut.ac.ir 
ييكسلهاى همسايه استفاده مىنمايند. در اين دســه از

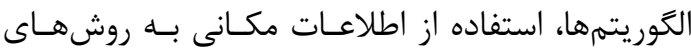

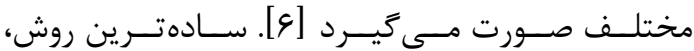

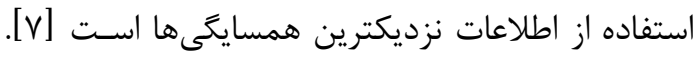

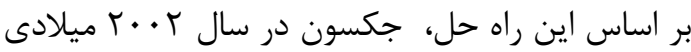

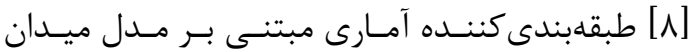

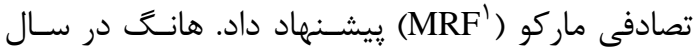

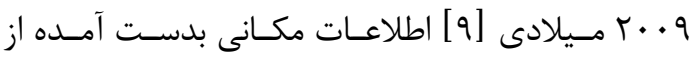

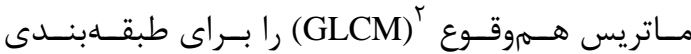

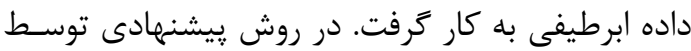

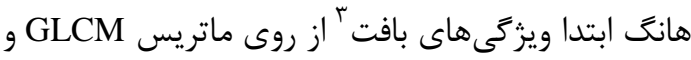

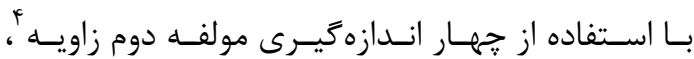

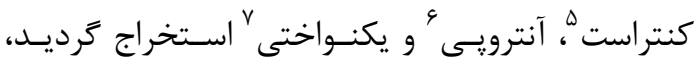

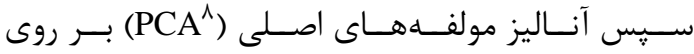
ويزگگىهاى بدست آمده اعمال گشته و مولفه هاى اصلى

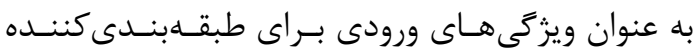

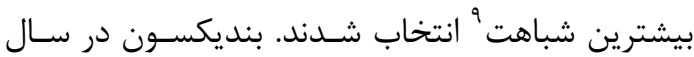

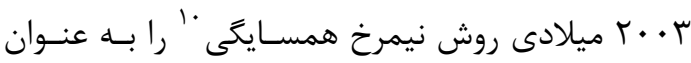

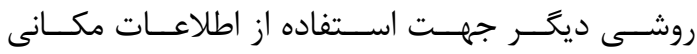

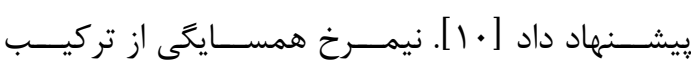
فيلترهاى باز "' و بسته با "تشـكيل يافتـه اسـت. اعمـال

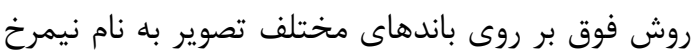

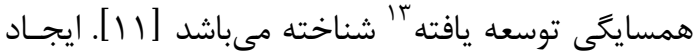

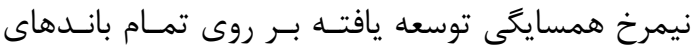

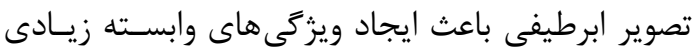

1 Markov Random Field

2 Gray Level Co-occurrence Matrix

3 Texture Features

4 Angular Second Moment

5 Contrast

6 Entropy

7 Homogeneity

8 Principal Component Analysis

9 Maximum Likelihood

10 Morphological Profiles

11Opening

12Closing

13 Extended Morphological Profiles
- 1- مقدمه

فن آورى سنجش از دور ابرطيفىى، در دو دهـه كذشـته

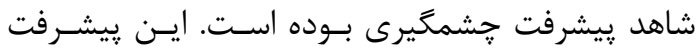
در طراحى و ساخت سنجندها و همجنين در توسعه و ييادهسازى روش هاى يردازش داده، بسيار مشهود است وته

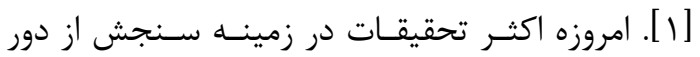
ابرطيفـى، بـر طبقــهبنـــى ايــن تصـاوير تاكيـد دارد. طبقه بندى يا تبديل تصاوير به نقشه موضـوعى در اثـر عواملى از جمله يِيجيدگى منطقه مورد مطالعه، انتخاب

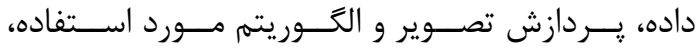
در معرض گالش جدى بوده و ممكن است بر موفقيـت

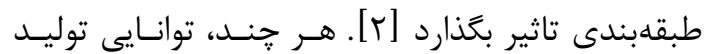
دادههايى با خصوصيات طيفـى، مكـانى و راديـومتريكى

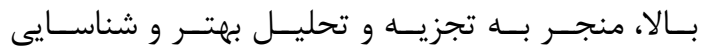
موفقيت آميز اهداف زمينى مىشود، ولى مشكلاتى نيـز

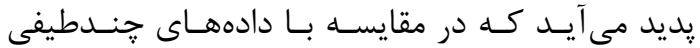
تجربه جديدى است. اولين مشكل حجم نسبتاً زياد اين

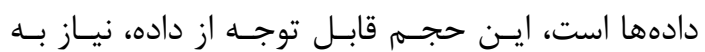
سختافزار و نرمافزارهاى ويزهاى جهـت يـردازش دارد.

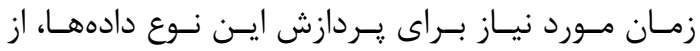

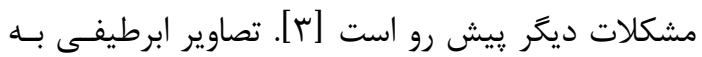
دليل داشتن تعداد باندهاى زياد، داراى مشـكل كمبـود

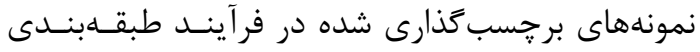
هستند. يكى از راه حلها جهت رفع اين مشكل، كاهش

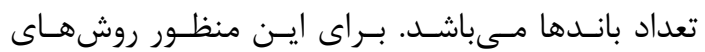

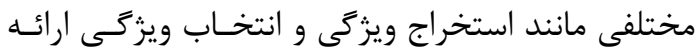
شده است [l[] بهطور كلى روشهاى طبقهبندى تصاوير ابرطيفى، به دو دسته تقسيمبندى مىشوند. دسته اول روشهاى طبقـــبندى مبتنى بر ريكسل بوده كه در آن هر ييكسل فقط

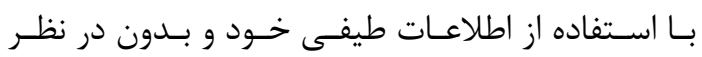
كرفتن اطلاعات موجود در ييكسل هاى همسايه به يـك

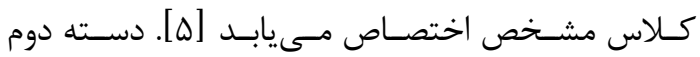
روشهاى طبقهبندى، روشهاى طبقهبندى طيفى -مكـانى بوده كه علاوه بر اطلاعات طيفى ييكسـلما از اطلاعـات 


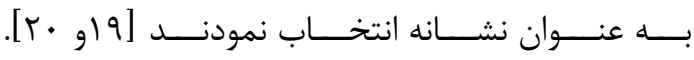

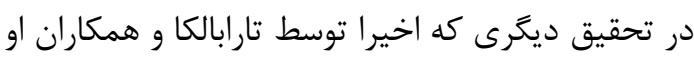

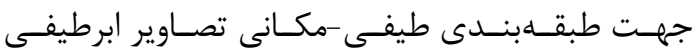

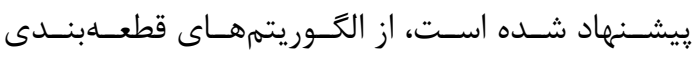

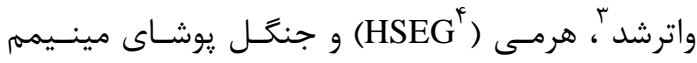

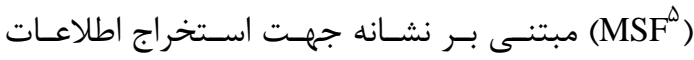

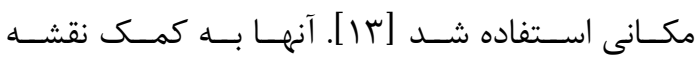

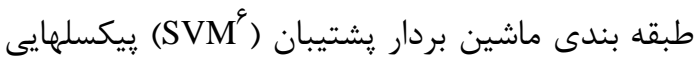

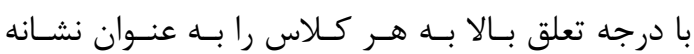

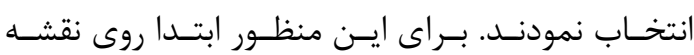

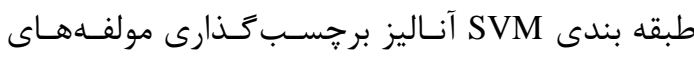

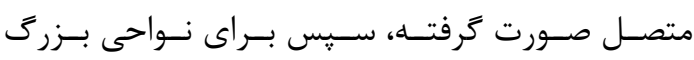

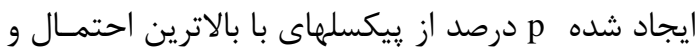
براى نواحى كوجى پيكسلهايى با درجه احتمال بيشـتر

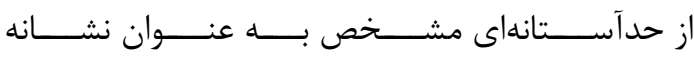
در نظر كرفته شد.

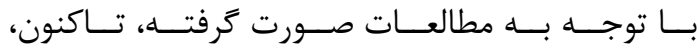

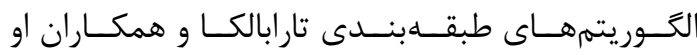

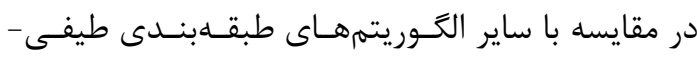

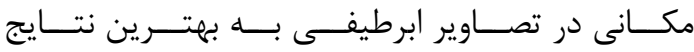

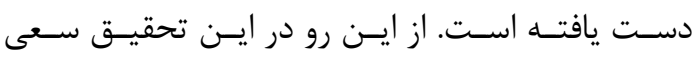

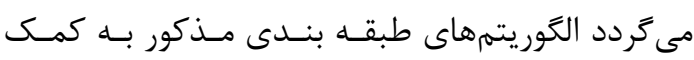
تكنيك كاهش ابعاد تصاوير ابرطيفى بهبــود داده شـود بـون.

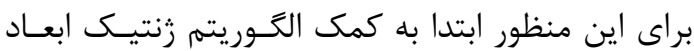

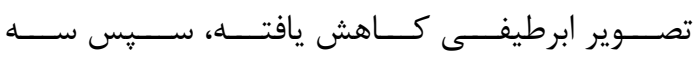

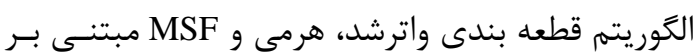

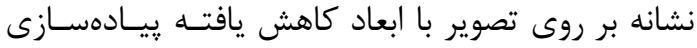

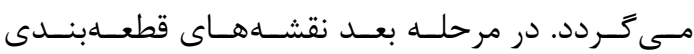

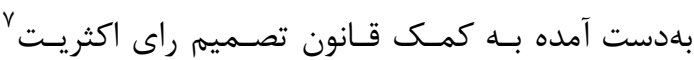

3Watershed

4 Hierarchical Segmentation 5 Minimum Spanning Forest 6Support Vector Machines 7Majority Voting
شده، از اينرو كاهش تعداد بانـدهاى تصـوير ابرطيفـى قبل از اعمال نيمرخ همسايكى الزامى اسـت. در همـين

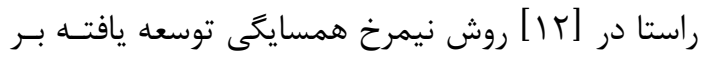

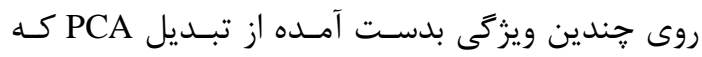
داراى بيشترين واريانس مى باشند، اعمال كرديد.

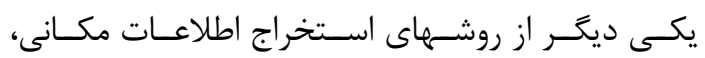

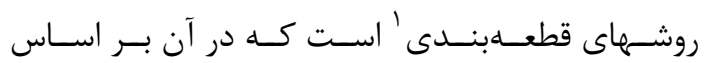
ويزگ گى هايى مانند يكنواختى، اشـياء موجـود در تصـوير

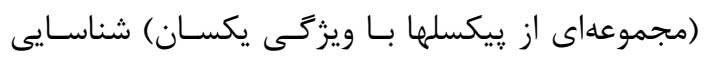

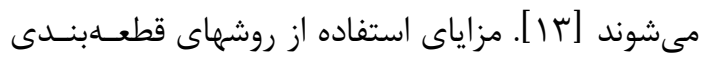

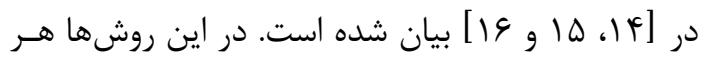
شىء به صورت همسايكى مكانى براى همه ييكسـلـهاى داخل آن شىء تعريف مىشود. اين راهحل براى مناطق يكنواخت بزرگ، همسايخى هاى بزرگى را ايجاد كـرده و

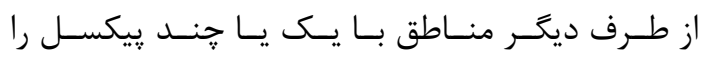

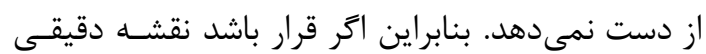
از اشــياء بـــر اســاس ســاختارهاى مكــانى در تصــوير

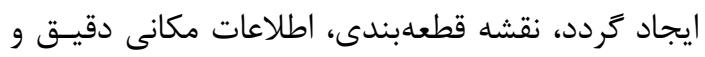

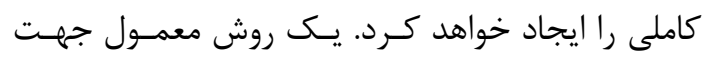
داشتن نتايج قطعهبندى دقيق، قطعهبنـدى مبتنـى بـر

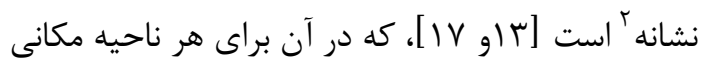

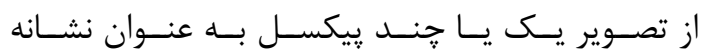
انتخاب شده، سيس نشانههاى بدست آمـده در فرآينـد قطعهبندى رشد يافته و منجر به ناحيـهاى مشـخص در نقشه قطعهبندى مىشـود. در تحقيقـات اوليـه صـورت

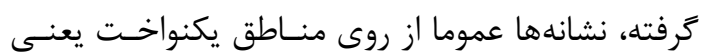

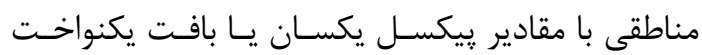

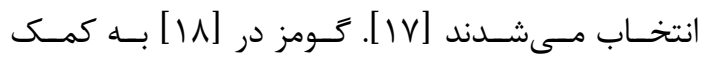

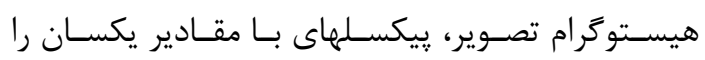
به عنوان نشانه اختيار نمود. نويل و همكارانش با انجـام

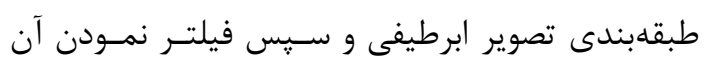

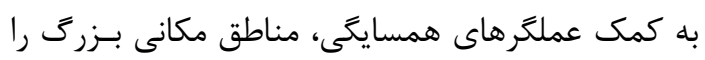

1Segmentation

2 Marker 


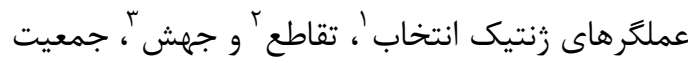

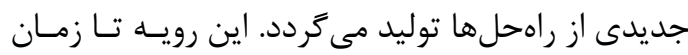

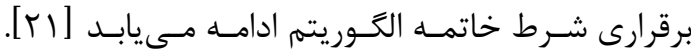
در الكوريتم زنتيك هر راهحل توسط يك رشـته بــهـ نـام

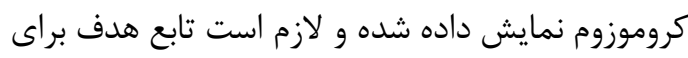

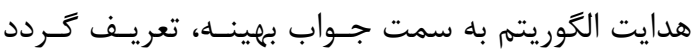

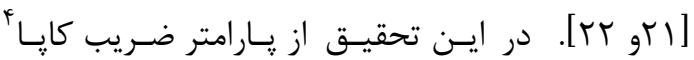

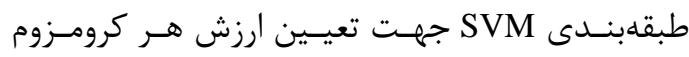
استفاده شد.

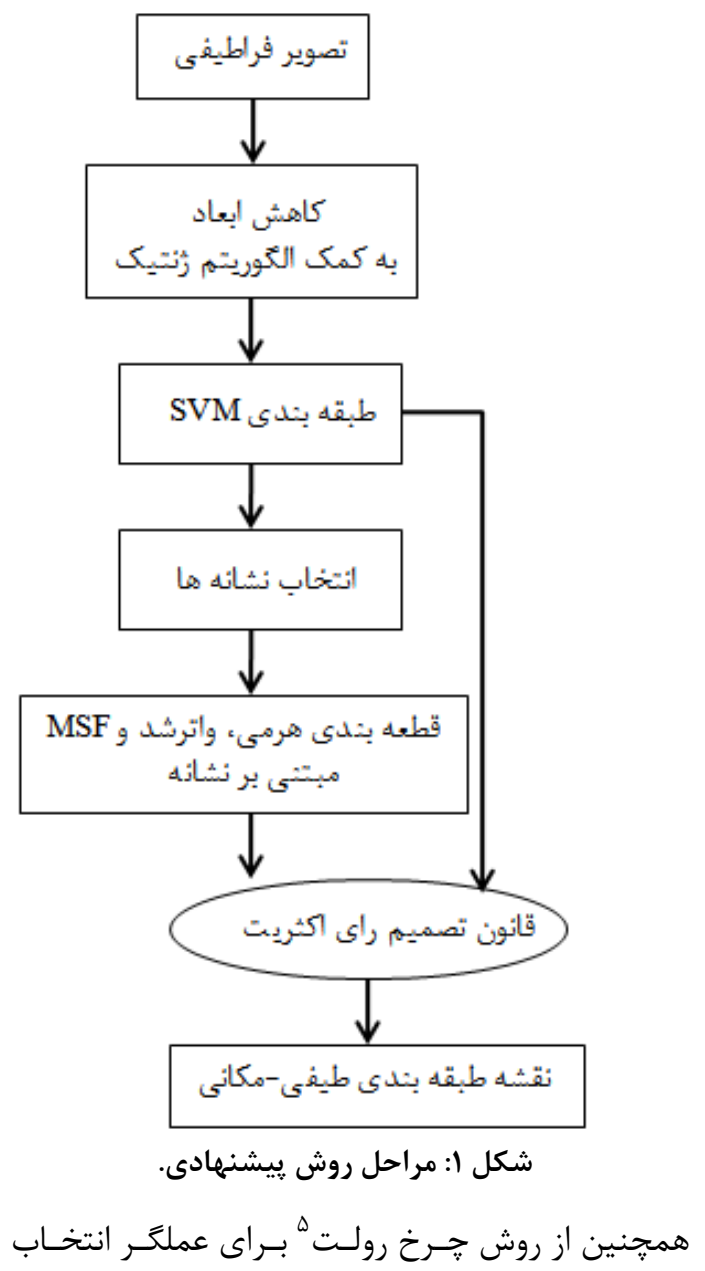

1 Select

2 Crossover

3 Mutation

4 Kappa Coefficient

5 Roulette Wheel
با نقشه طبقهبندى SVM تركيـب مسىشـود. در ادامـه

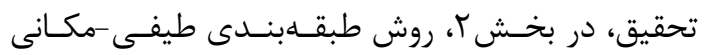

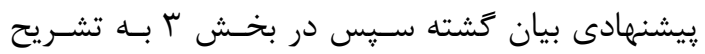

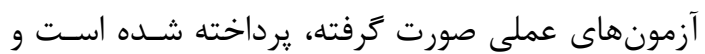

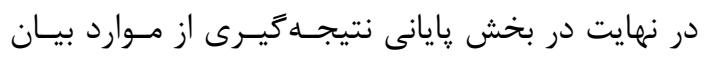
شده ارائه مى كردد.

$$
\text { r - rوش ييشنههادى }
$$

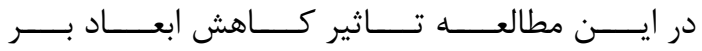

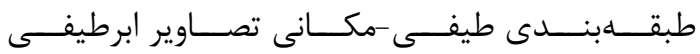

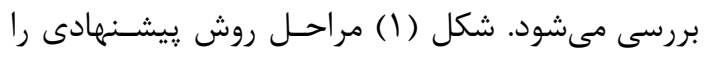
نشان مى دهد. همانطور كه در اين شكل مشخص است،

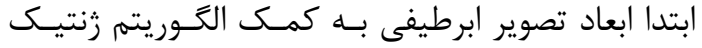

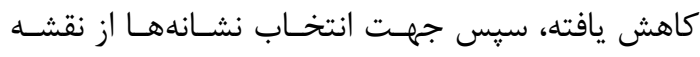
طبقلبندى SVM استفاده و ويكسل هاى با درجه تعلـق بالا به يك كلاس به عنوان نشانه انتخاب مسىشـوند. در مرحله بعد بر روى نشانههاى بدستآمده الخوريتمهـاى

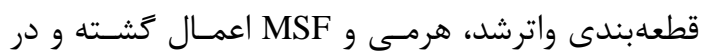
نهايت به كمك قانون تصميم راى اكثريـت نقشـهـهـاى قطعهبندى با نقشه طبقهبندى SVM تركيب مى در قـانون تصـميم راى اكثريـت همــانطورى كـــه در

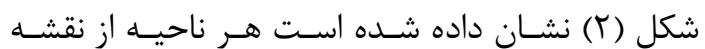
قطعهبندى به كلاسى كه اكثر ييكسـلهاى آن در نقشـهـ طبقهبندى تعلق دارند، اختصاص مى يابد.

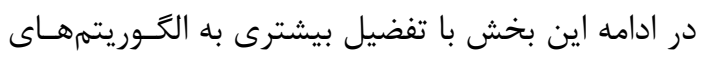
زنتيك، واترشد، هرمى و MSF يرداخته شده است.

\section{r-1- الكوريتم زنتيك}

الكوريتم ززنتيكـ_ كه جـزء تكنيـكـهـاى بهينـهسـازى

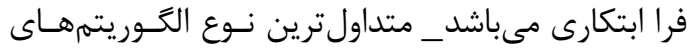

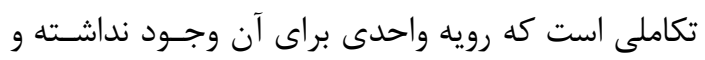
داراى رويهاى تكرارى است [إr]. در طى هر بار تكـرار

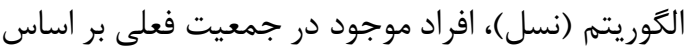

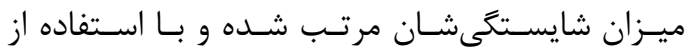




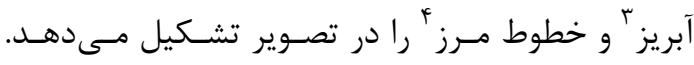

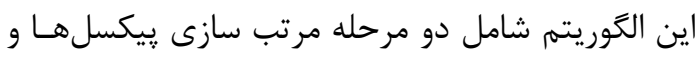
جارى شدن سيل است. مرحله مرتب سازى بِيكسلهـان

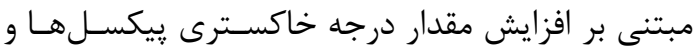

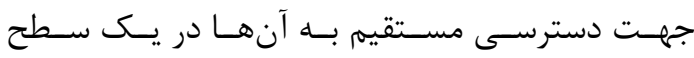
مشخصى از مقادير درجه خاكسترى مى باشد. همجنـين

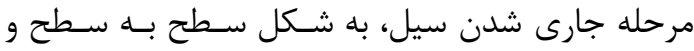

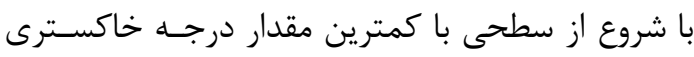

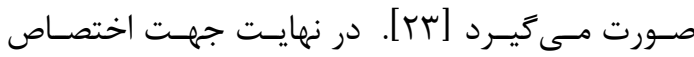
هر ييكسل واترشد به ناحيه موردنظر، بردار ميانه بـراى

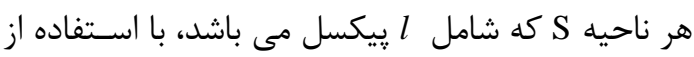
رابطه (Y) محاسبه مىشود.

$$
S=\arg \min _{s \in S}\left\{\sum_{j=1}^{l}\left\|s-s_{j}\right\|\right\} \quad \text { رابطه(ب) محند) }
$$

همانطورى كه از رابطه (r) مشخص اسـت بـردار فـوق

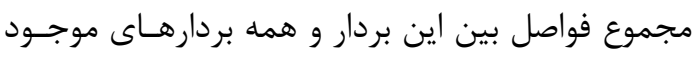

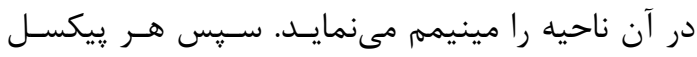

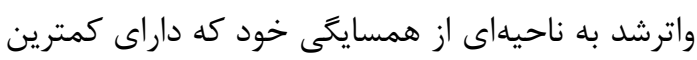

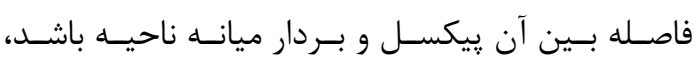
تعلق مى گيرد.

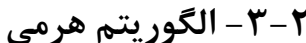

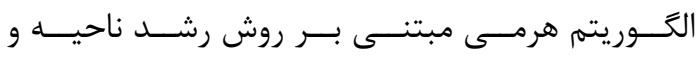

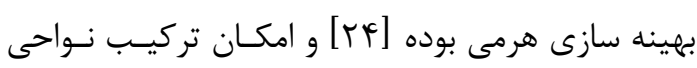
مكـانى غيرمجـاور را بـهـ وسـيله يـارامتر ورودى فراهم مىسازد. يارامتر

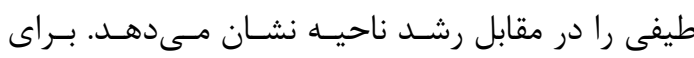
الكوريته هرمى فقط نواحى مكـانى مجـاور $S_{w g h t}=0$

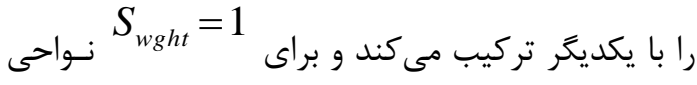

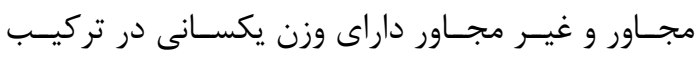

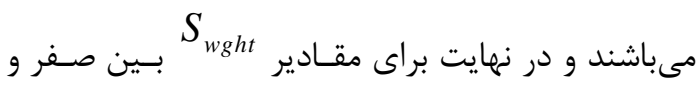

3Catchment basins 4Ridge lines
استفاده شده است. در ايـن روش احتمـال انتخـاب هـر

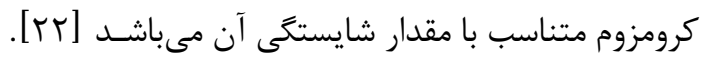

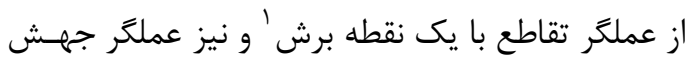

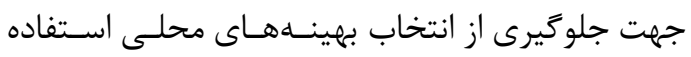

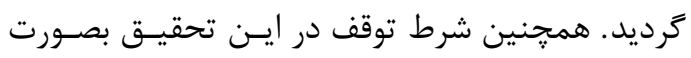

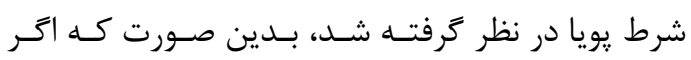

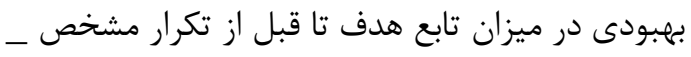

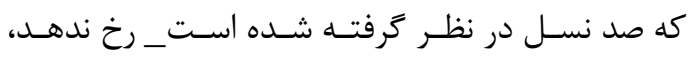

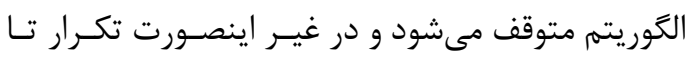

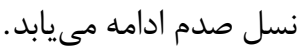
r-r - r- الكوريتم واترشد

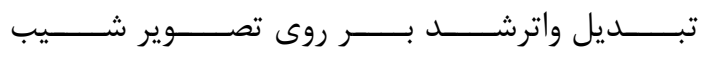

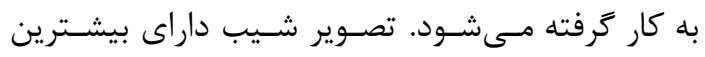

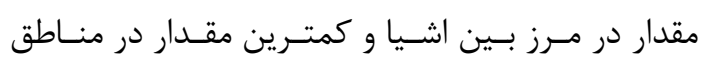

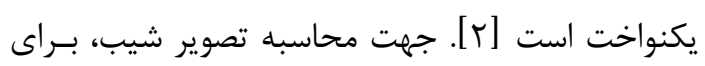

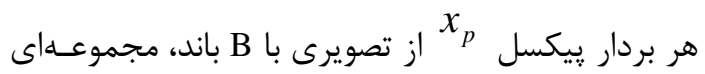

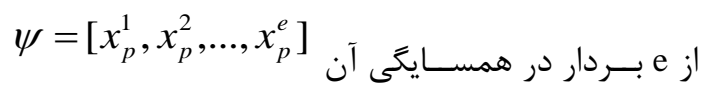

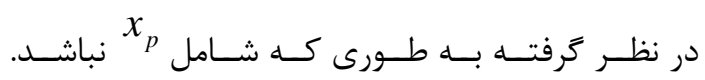

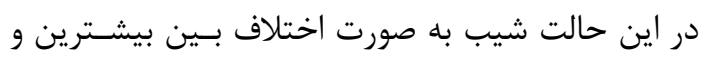

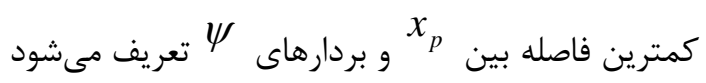

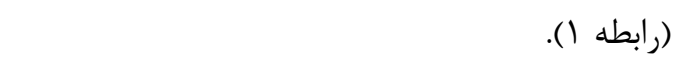
$\nabla_{\psi, d}\left(x_{p}\right)=-\inf \left\{d\left(x_{p}, x_{p}^{j}\right)\right\}_{j \in \psi} \quad$ (1) (1) در اين رابطه ه معرف شيب، ( , d معـرف فاصـله بـين

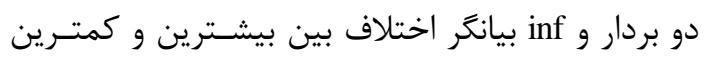

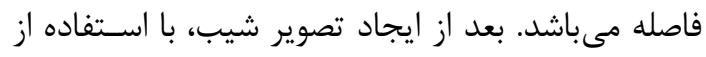

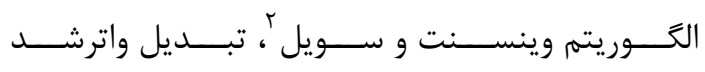

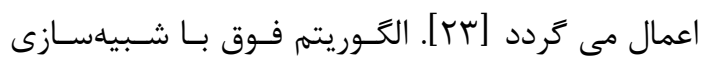

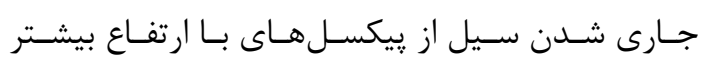

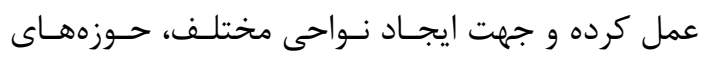

1 Single Point

2Vincent and Soile 
مقدار معيار عدم تشابه و تركيب آنها

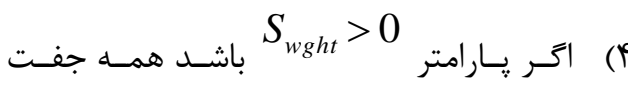
نواحى غير مجاور با مقدار معيـار عـدم تشــابه

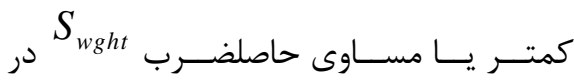

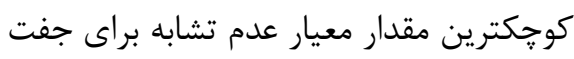
نواحى مجاور، تركيب مى كردد.

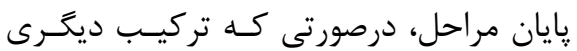

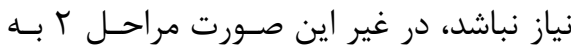

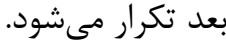

يــى، تركيـب نـواحى مجــاور در مقايسـهـ بــا نـواحى غيرمجاور داراى برترى

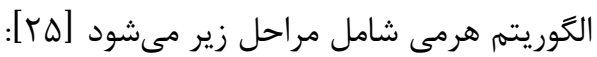

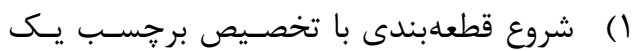

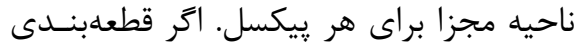

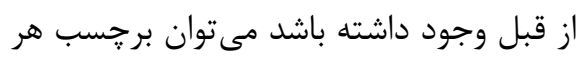
بيكسل را بر اساس آن انجام داد.

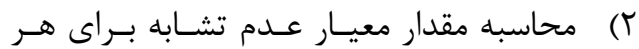

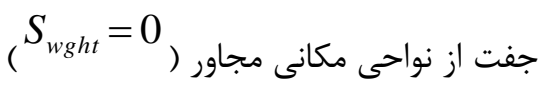

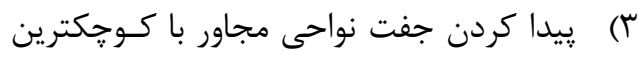

\begin{tabular}{|l|l|l|l|l|}
\hline 1 & 1 & 1 & $r$ & $r$ \\
\hline 1 & 1 & 1 & $r$ & $r$ \\
\hline 1 & 1 & 1 & $r$ & $r$ \\
\hline 1 & $r$ & $r$ & $r$ & $r$ \\
\hline$r$ & $r$ & $r$ & $r$ & $r$ \\
\hline
\end{tabular}

نقشه قطعه بندى

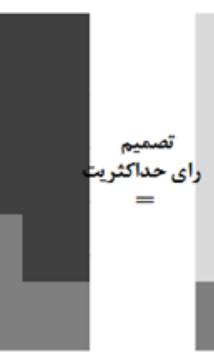

نقشه طبقه بندى طيفى

نقشه طبقه بندى طيفى -مكانى

شكل r: مثالى از قانون تصميم راى اكثريت در نواحى قطعدبندى شده

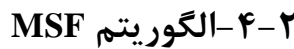

در الكوريتم MSF هر קيكسل بـه صـورت يـك راس از كراف رئوس و يالهاى كراف هستند، در نظر كرفته مىشـود، به طورى كه هر يال ي ييكسلهاى همسايتى را به هم وصل مى كند. عـلاوه بـر اين، هر يال

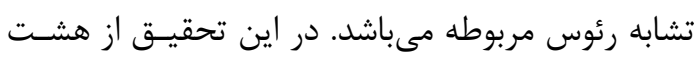

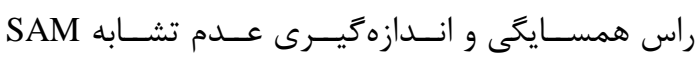
جهت محاسبه وزن يالها، استفاده شد [عץ].

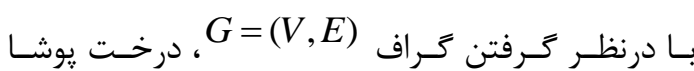

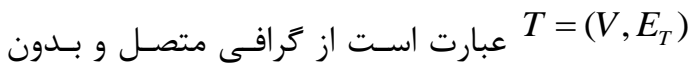

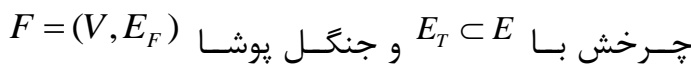
كرافى منفصل و بدون جـرخش بـا
لازم به ذكر است جهت محاسبه عدم تشابه در الكوريتم

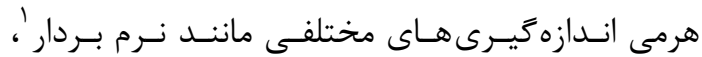

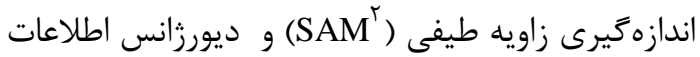

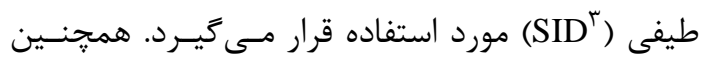

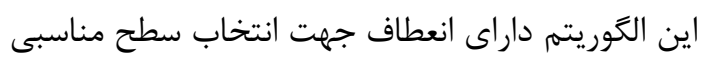

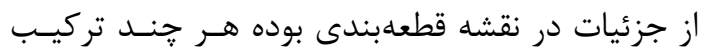

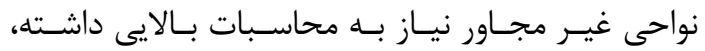

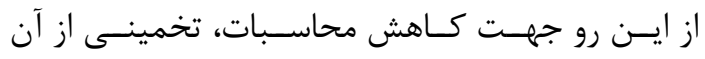
بــه صـورت الخَـوريتم هرمسى بازخشــتى ( RHSEG) به كار زرفته مىشود.

1 Vector Norms

2 Spectral Angle Measure

3 Spectral Information Divergence

4 Recursive HSEG 
رشد يافته روى ريشههاى

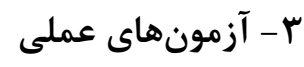

r- ا- دادههاى ابرطيفى مورد استفاده

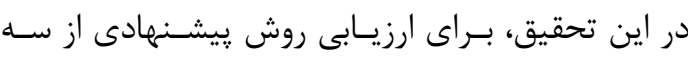

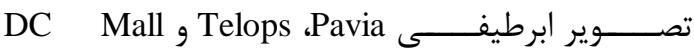

استفاده شد كه مشخصات ايـن تصـاوير در جـدول (1) خلاصه شدهاند. براى هر يك از كلاسها در هر سـه داده تصويرى، به صورت تصادفى حدود • إ درصد از نمونـهـ-

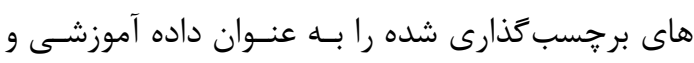
مابقى آنها يعنى حدود •9 درصد را به عنوان داده تست

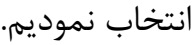

[ع]. همجنين درخت بوشاى مينيمم به صورت درخت

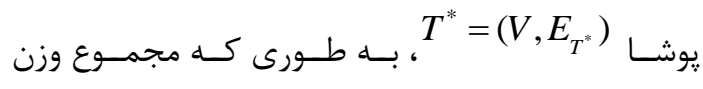
يالهاى آن كمترين باشد تعريف مى كردد (رابطه ؟). $T^{*} \in \arg \min _{T \in S T}\left\{\sum_{e_{i, j} \in E_{T}} w_{i, j}\right\} \quad$ (T) در رابطه (ب)، ST مجموعه تمام درختهاى يوشا گراف G مىباشد. G از طـرف ديخـ MSF روى m راس مجــا $\}^{\prime}$ شامل پيدا كردن جنكل يوشا طورى كه هر درخت مجزا *F ، از ريشه مجموع وزن يالهاى آن كمترين است (رابطه ؟ُ).

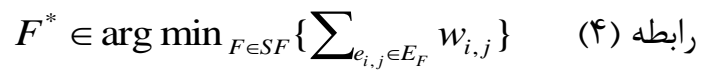

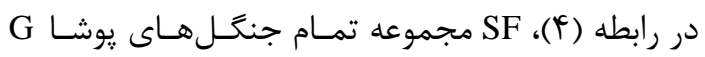
جدول ا: خصوصيات تصاوير ابرطيفى مورد استفاده

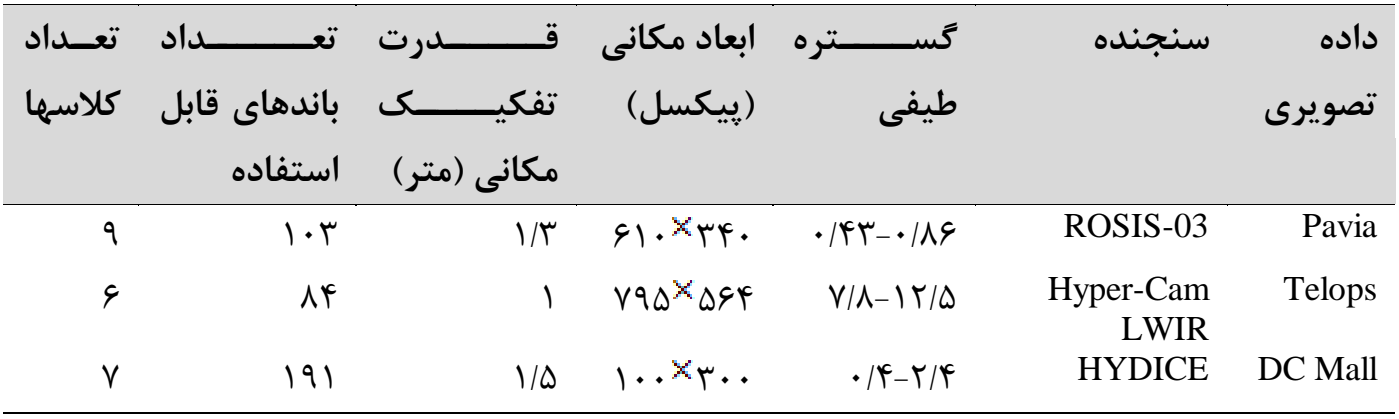

بــه ترتيـب برابـر بـا ها • و ه • • • در نظـر كرفتـهـ شـد. همجنين براى ايجاد تناسب بين دو يارامتر دقت و زمان

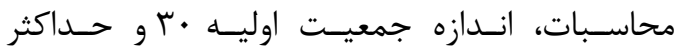

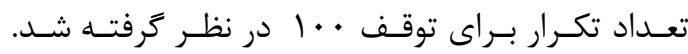

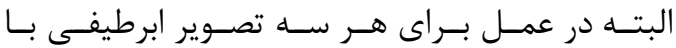

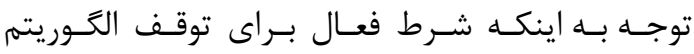

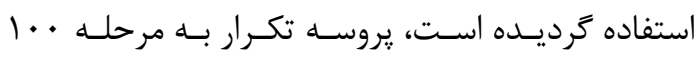

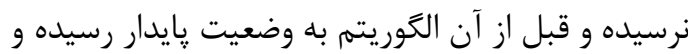

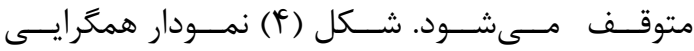

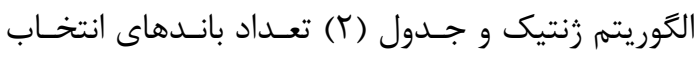

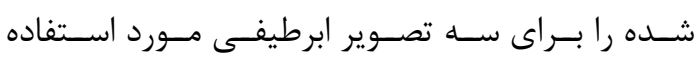

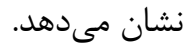

شــكل (r) نمـــايش رنخــى ســهـ تصــوير ابرطيفـى

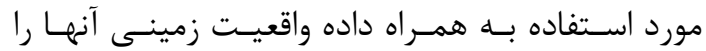
نشان مىدهد. در تصوير Telops مقادير بيكسلها برابر با فيا مقادير راديانس بوده، از ايــن رو بايسـتى قبـل از انجـام آزمــونهـا، تصـحيحات اتمسـفرى بــر روى تصــوير

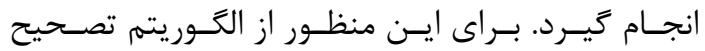

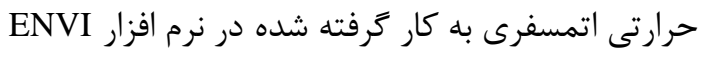

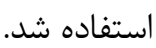

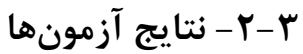

در آزمونهاى صـورت كرفتـه بــراى الخــوريتم زنتيــ، كرومزومها داراى زنهايى برابر با تعداد باندهاى تصـوير

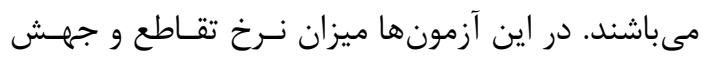




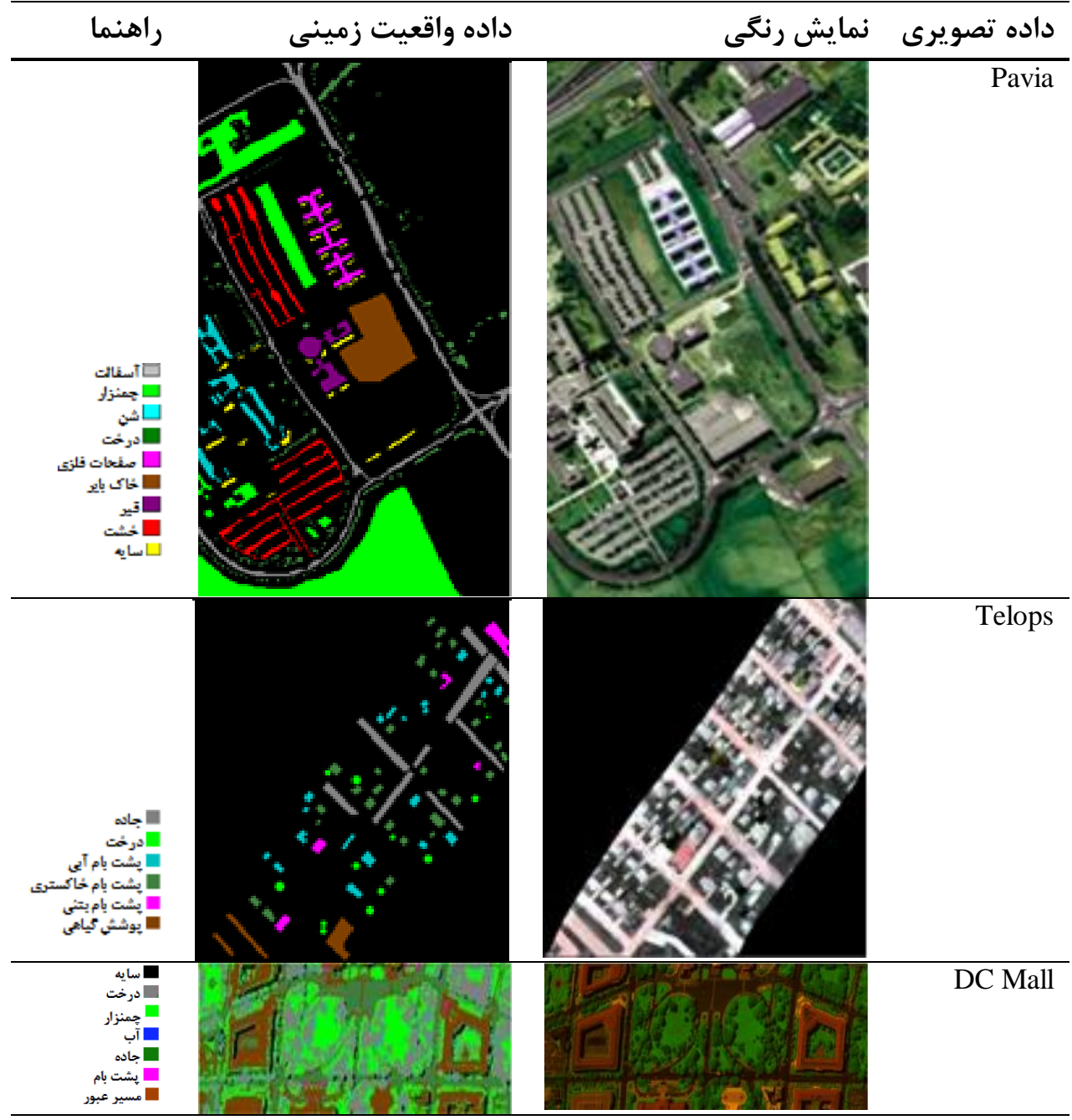

شكل r: نمايش رنغى و داده واقعيت زمينى تصاوير ابرطيفى مورد استفاده

استفاده شد [TV]] مقادير دو يارامتر تنبيه ؟ (C) و كرنل

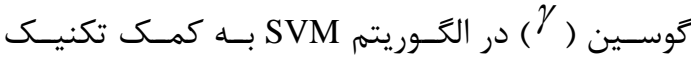

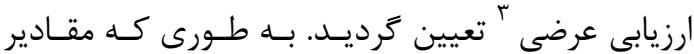

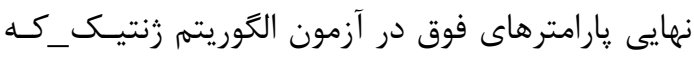

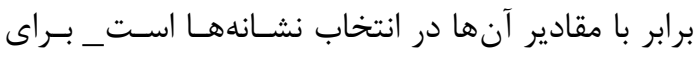

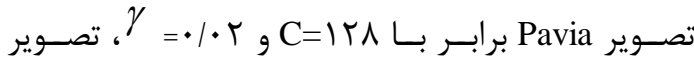
DC Mall برابر با Telops

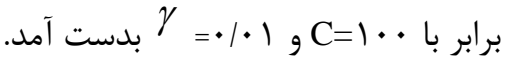

2Penalty parameter

3 Cross validation
جدول r: تعداد باندهاى انتخاب شده با بكارگيرى الكَريتم زنتيك در سه تصوير ابرطيفى

\begin{tabular}{|c|c|c|}
\hline انتخاب شده & تعداد باندهاى & داده تصويرى \\
\hline & $\Delta r$ & Pavia \\
\hline & FV & Telops \\
\hline & سو & DC Mall \\
\hline
\end{tabular}

همانطور كه در بخش r-1 بيان شد، براى تعيين ارزش

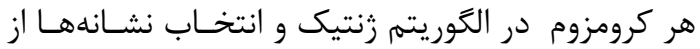

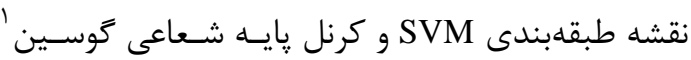

1Gaussian Radial Basis Kernel 

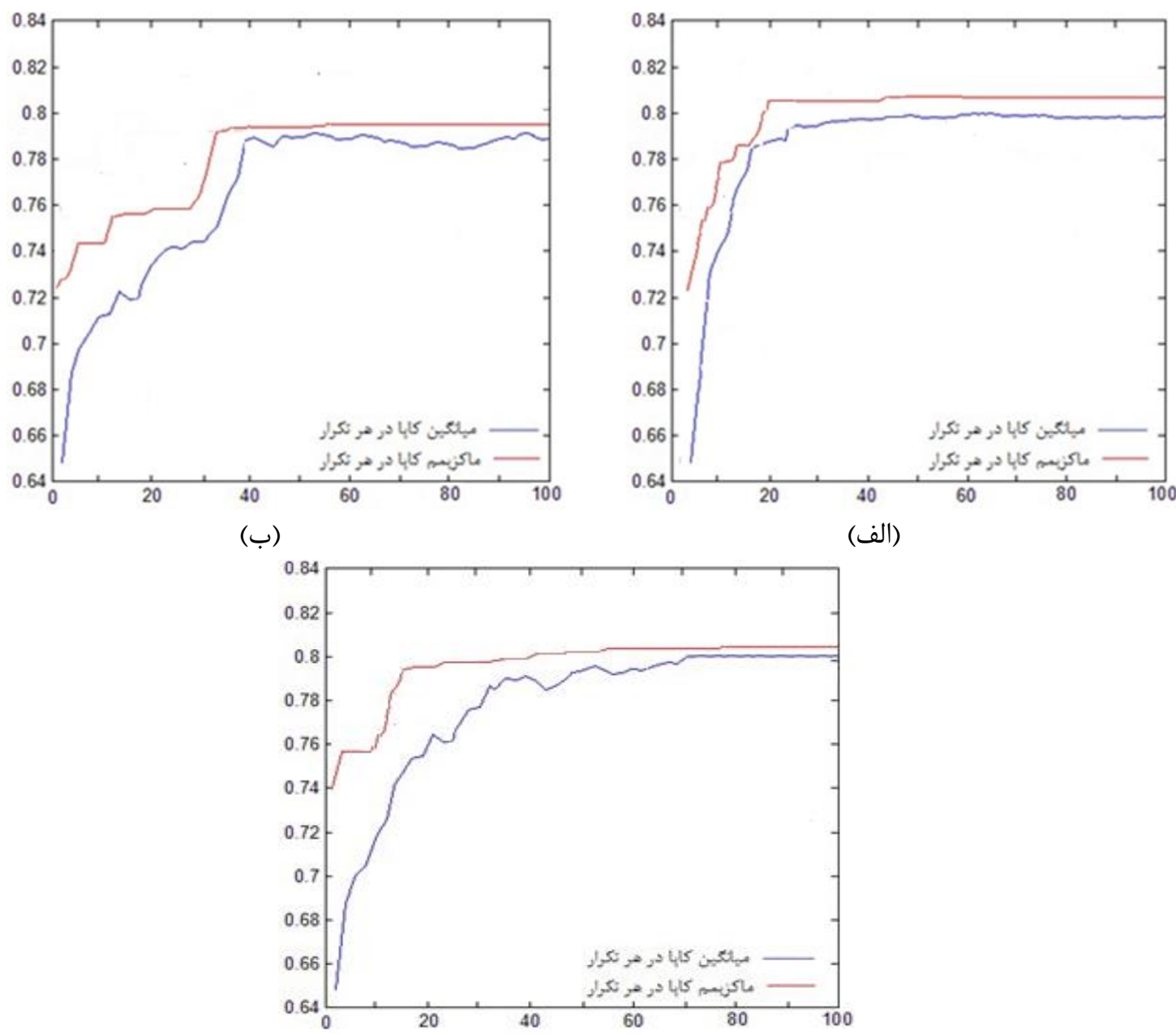

(الف)

(ج)

شكل f: نمودار همكر ايى الكَوريتم رزنتيك در تصوير (الف) Pavia) (ب) Telops و (ج) DC Mall (ج) (ب)

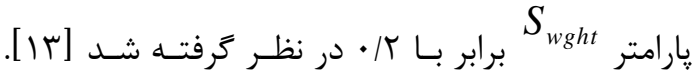

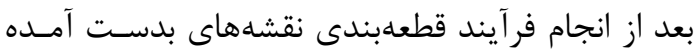

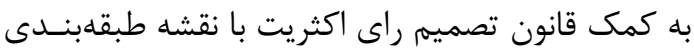

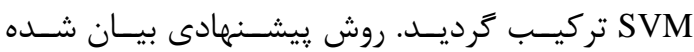
در اين تحقيق، با الكوريتههاى واترشد مبتنى بر نشـانه (M-watershed)، هرمى مبتنى بر نشانه (M-RHSEG)

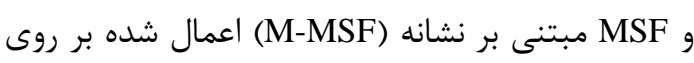
تمام باندهاى تصوير مقايسه شد.

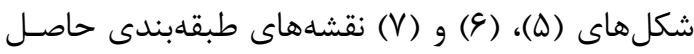

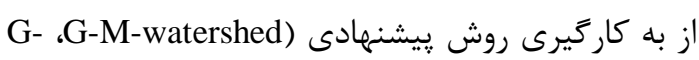

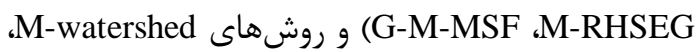
M-MSF و ا براى سـه تصـوير ابرطيفى وفى M-RHSEG
سيس آناليز برجسب קذارى مولفههاى متصل بر اسـاس

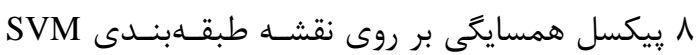

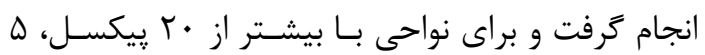

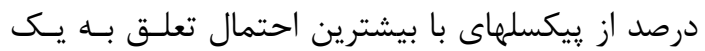

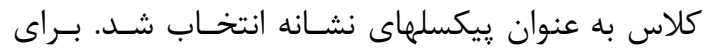

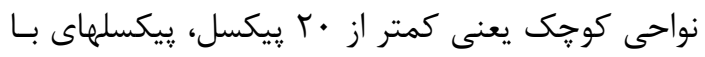

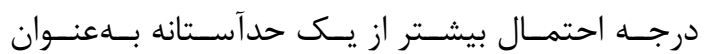

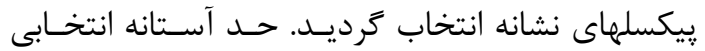

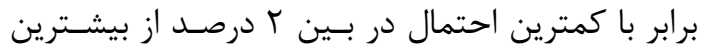

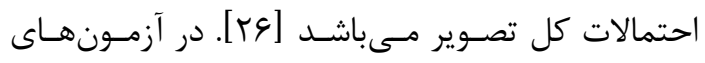

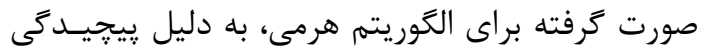
مناطق شهرى تصاوير ابرطيفى مـورد اسـتفاده، مقـدار 
تصوير Pavia و Telops و DC Mall نقشـه طبقـهبنـدى G-M-MSF مناطق يكنواخترى است.
نشـان مـى دهــد. در اسـامى فـوق حــرف G نشـانكر الخوريتم زنتيك و حرف M بيانغر به كارگيرى نشانههـا قبل از الكوريتمهاى قطعهبندى واترشد، هرمسى و MSF

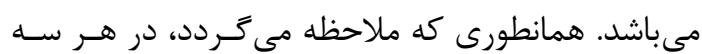
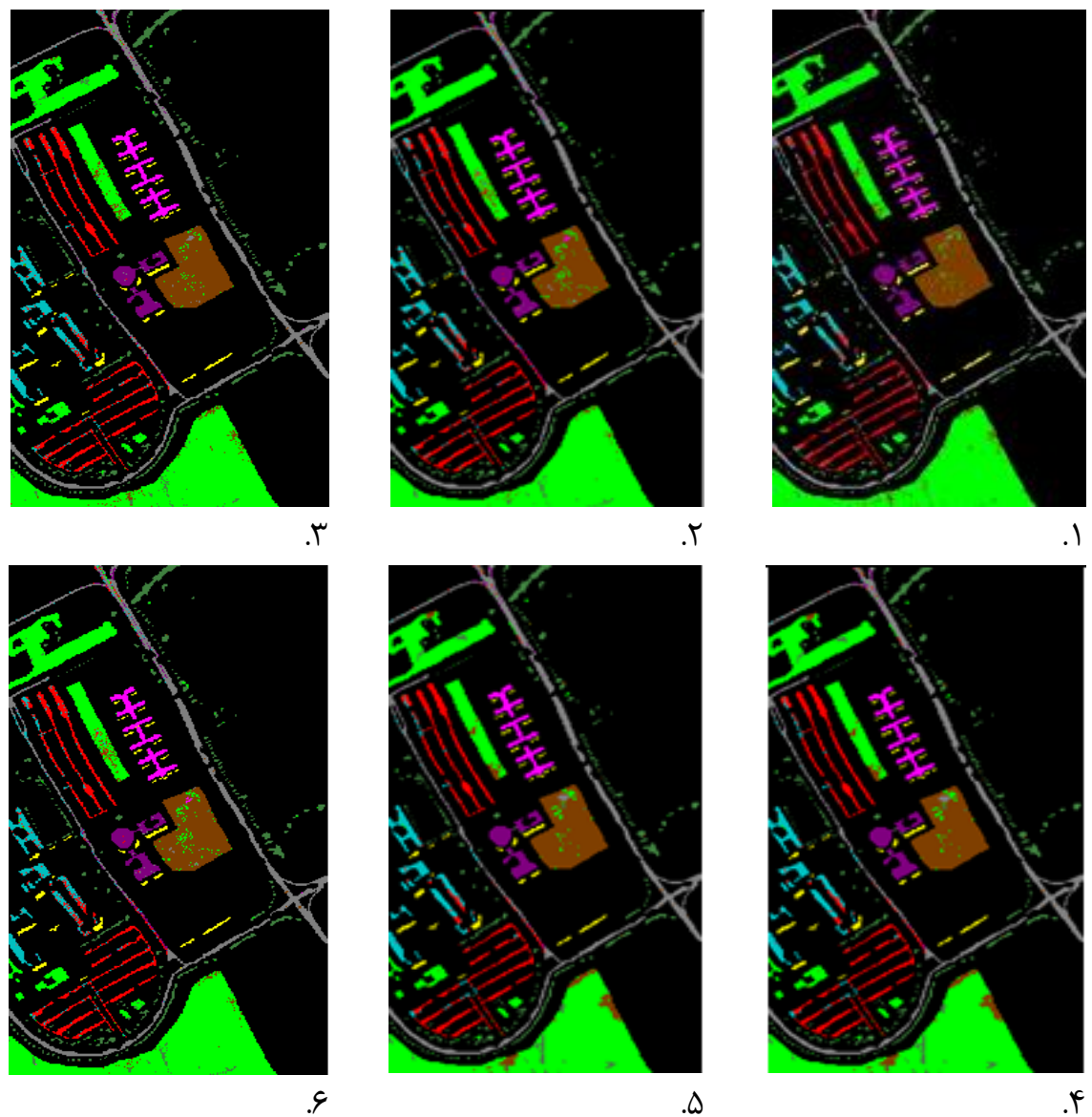

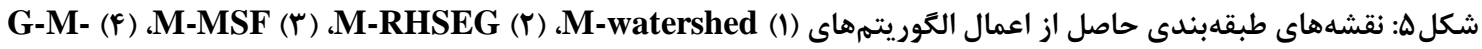
Pavia بر بر روى تصوير ابرطيفى G-MSF (\&)، G-M-RHSEG (ه) ،watershed

،Pavia

$$
\begin{aligned}
& \text { طبقــهبنـدى بدسـتآمــده از تصـاوير ابرطيفـى } \\
& \text { DC Mall Telops }
\end{aligned}
$$

$$
\begin{aligned}
& \text { به منظور ارزيابى دقت آزمونهاى صورت گرفتـه، ابتـدا }
\end{aligned}
$$

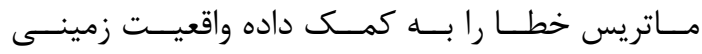

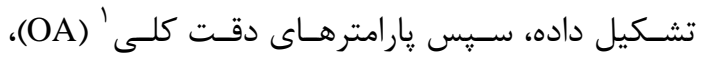

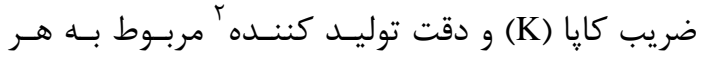

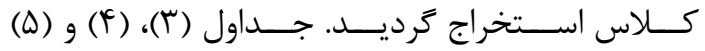

$$
\begin{aligned}
& \text { بـــه ترتيــب مقــادير يارامترهـــاى دقـت نقشــهـهــاى }
\end{aligned}
$$

1 Overall Accuracy

2 Producer Accuracy 


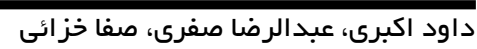
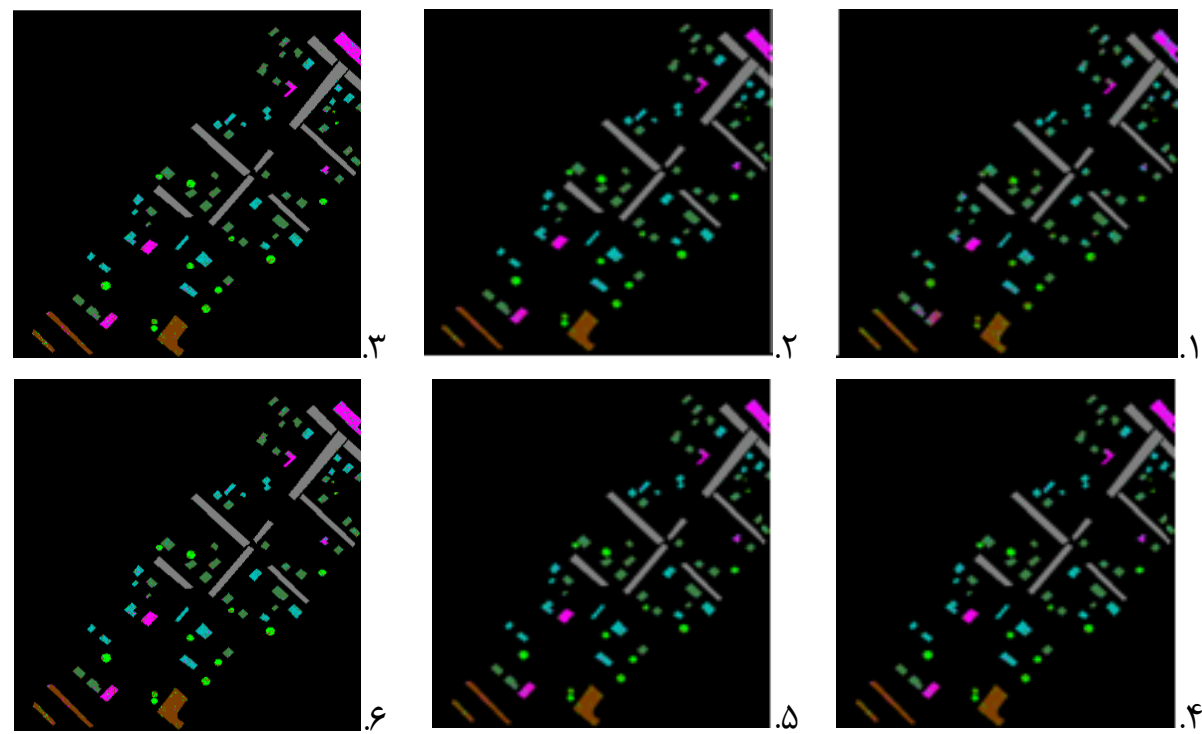

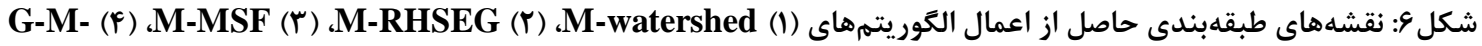
Telops بر روى تصوير ابرطيفى G-M-MSF (\&)،G-M-RHSEG (ه) ،watershed
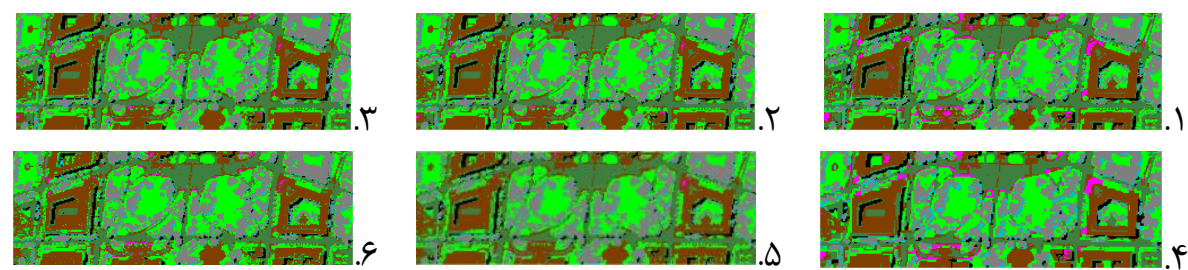

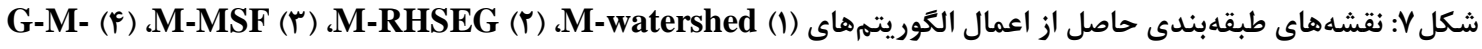
DC Mall بر روى تصوير ابرطيفى G-M-MSF (\&)،G-M-RHSEG (ه) ،watershed

جدول r: مقادير هارامترهاى دقت آزمونهاى صورت ترفته براى تصوير ابرطيفى Pavia

\begin{tabular}{|c|c|c|c|c|c|c|}
\hline G-M-MSF & G-M-RHSEG & G-M-watershed & M-MSF & M-RHSEG & M-watershed & \\
\hline$\Delta r$ & س & س & r & r & 1. & تعداد باند \\
\hline $9 \wedge / 1$ & $9 \pi / 0$ & $9 \cdot 11$ & $94 / V$ & $94 / 1$ & $91 / 4$ & $\mathrm{OA}$ \\
\hline $99 /$. & $91 / 1$ & $19 / 9$ & $9 r / 9$ & $94 / \pi$ & $9 \cdot 19$ & $\mathrm{~K}$ \\
\hline $9 Q / 4$ & $q \mu / V$ & $91 / 0$ & $q p / r$ & $q 9 / r$ & $94 \%$ & آسفالت \\
\hline $9 V / 1$ & $9 \Delta / \uparrow^{c}$ & $9 \Delta / \cdot$ & $9 \varphi / 1$ & $9 \mathrm{~V} /$. & $94 / 1$ & جمنزار \\
\hline$\Lambda \Lambda / \vee$ & $1 r / 9$ & $V \bowtie / I$ & $\Lambda \omega / \vee$ & $\Lambda F / Q$ & $\vee 9 / 9$ & شن \\
\hline $99 / 4$ & $9 \vee / 0$ & $\wedge 9 / 0$ & १९/. & $91 / 9$ & $94 / 5$ & درخت \\
\hline $99 / 4$ & $99 / 0$ & $9 \mathrm{~V} / \cdot$ & $9 \Delta / \uparrow^{c}$ & $q V / r$ & $9 \Delta / r$ & صفحات فلزى \\
\hline $1+$. & $9 \Delta / 9$ & $9 \Delta / 9$ & $q \Delta / r$ & $99 / 0$ & $94 / 4$ & خاى باير \\
\hline $99 / 9$ & $99 / V$ & $91 / 9$ & $94 / r$ & $q r / r$ & $9 \Delta / 1$ & قير \\
\hline$q p / D$ & $\Lambda \Lambda / 1$ & $\Lambda \wedge / \cdot$ & $q r / r$ & $q p / d$ & $q \cdot / r$ & خشت \\
\hline $99 /$. & $91 / 9$ & $91 / 1$ & $99 / 0$ & $94 / 1$ & $19 / 9$ & سايه \\
\hline
\end{tabular}


جدول Felops جقادير يارامترهاى دقت آزمونهاى صورت گرفته براى تصوير ابرطيفى

\begin{tabular}{|c|c|c|c|c|c|c|}
\hline $\begin{array}{l}\text { G-M- } \\
\text { MSF }\end{array}$ & $\begin{array}{r}\text { G-M- } \\
\text { RHSEG }\end{array}$ & $\begin{array}{r}\text { G-M- } \\
\text { watershed }\end{array}$ & M-MSF & $\begin{array}{r}\text { M- } \\
\text { RHSEG }\end{array}$ & $\begin{array}{r}\text { M- } \\
\text { watershed }\end{array}$ & \\
\hline iv & FV & FV & $\Delta f$ & NF & $\lambda F$ & تعداد باند \\
\hline $9 \pi / 1$ & $\Lambda \varepsilon / \Delta$ & $\Lambda T / r$ & $9 \cdot 10$ & $19 / \pi$ & $\Lambda T / \Delta$ & $\mathrm{OA}$ \\
\hline$q+/ r$ & $\Lambda \kappa / q$ & $\Lambda \cdot / \Gamma$ & $1 N / 9$ & $\Lambda V / r$ & $1 \cdot / 9$ & $\mathrm{~K}$ \\
\hline $99 / \%$ & $99 / 9$ & $9 / / 1$ & $99 / /$ & $99 / 9$ & $99 / \%$ & جاده \\
\hline $9 Y / T$ & $\Lambda \varepsilon / \Gamma$ & $V I / f$ & $q \cdot / r$ & $\wedge V / 9$ & $11 / 9$ & درخت \\
\hline $19 / 9$ & $\Lambda \Delta / \uparrow^{q}$ & $V \Psi / \Gamma$ & $19 / 9$ & $\Lambda N / V$ & $\Lambda V / q$ & يشتبام آبى \\
\hline$\Lambda N / r$ & $\Lambda \Delta / V$ & $\Lambda 1 / \Lambda$ & $q \cdot / p$ & $M N / \mathcal{F}$ & $\Lambda \Delta / \mu$ & يشتبام خاكسترى \\
\hline$\wedge \wedge / \bullet$ & $\Lambda \mathrm{V} / \mathrm{\Lambda}$ & $\vee 9 / 9$ & $\Lambda \Gamma / r$ & $\Lambda \mu / \mathcal{F}$ & $\Lambda \cdot 10$ & يشتبام بتنى \\
\hline $94 / 4$ & $91 / \%$ & $9 \& / 1$ & $9 \pi / \pi$ & $94 / \pi$ & $9 T / 4$ & يوشش گياهى \\
\hline
\end{tabular}

جدوله: مقادير يارامترهاى دقت آزمونهاى صورت كرفته براى تصوير ابرطيفى DC Mall

G-M-MSF G-M-RHSEG G-M-watershed M-MSF M-RHSEG M-watershed

\begin{tabular}{|c|c|c|c|c|c|c|}
\hline Gr & Gr & ع & 191 & 191 & 191 & تعداد باند \\
\hline$q \& / F$ & & $\Lambda \Delta / 1$ & $94 / 1$ & $q 4 / r$ & $\Lambda N / 1$ & $\mathrm{OA}$ \\
\hline $9 \pi / \Delta$ & $91 / \cdot$ & $11 / 9$ & $q \cdot / V$ & $91 / \pi$ & $\Lambda \bowtie / \varphi$ & $\mathrm{K}$ \\
\hline $9 \varepsilon / \Gamma$ & $94 / 9$ & $94 / 0$ & $9 \Delta / \pi$ & $94 / 9$ & $99 / 4$ & سايه \\
\hline $9 V / r$ & $91 / 1$ & $91 / 4$ & $9 \Delta / r$ & $q 4 / \pi$ & $91 / 1$ & درخت \\
\hline$\Lambda V / \Delta$ & $\Lambda N / \Lambda$ & $\Lambda \cdot / \Lambda$ & $\Lambda \Lambda / \Delta$ & $1 \wedge / 9$ & $\Lambda T / F$ & جمنزار \\
\hline $9 \pi / \Delta$ & 19/• & ^9/. & $9.1 \cdot$ & $19 / 9$ & $9 \cdot 10$ & آب \\
\hline$q r / f$ & $q \cdot / r$ & MN/V & $9 \cdot 11$ & $91 / 9$ & $\wedge V / q$ & جاده \\
\hline $9 \wedge / \Delta$ & $98 / 9$ & $94 / 9$ & $9 \varsigma / 4$ & $91 / 4$ & $90 / 9$ & يشتبام \\
\hline$q \mu / r$ & $\Lambda V / \mathcal{A}$ & $11 / V$ & $q \cdot / r$ & $19 / 1$ & $\Lambda \varepsilon / T$ & مسير عبور \\
\hline
\end{tabular}

Telops بِارامتر دقت كلى است. ميزان كاهش در تصوير

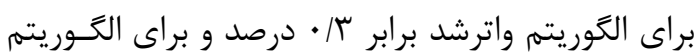

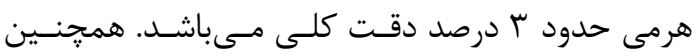

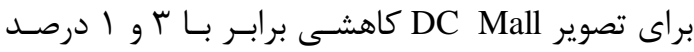

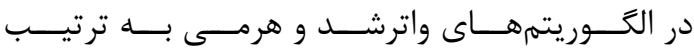
رخ داده است. اين كاهش مقادير دقـت در دو الخَّوريته

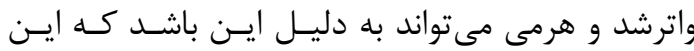

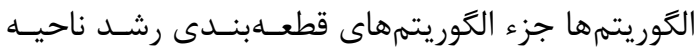

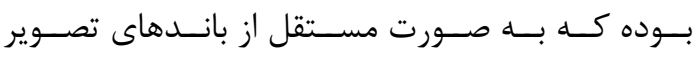

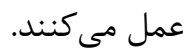

همانطورى كه از اين جداول و شكل (^) مشخص است

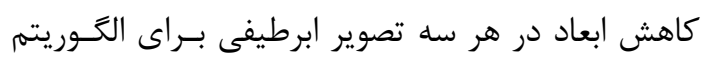

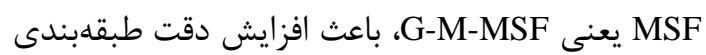

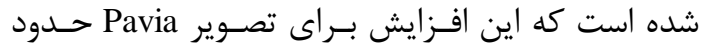

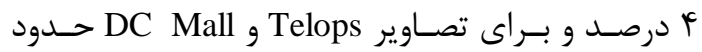

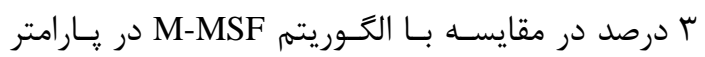

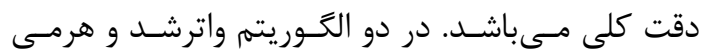
كاهش ابعاد سبب كاهش دقت طبقهبندى شــده اسـت، كه اين كاهش براى تصوير Pavia در الكَوريتم واترشـد

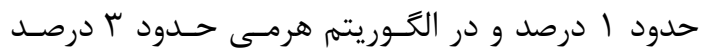


تاثير انتخاب ويزَكى به كمك الكَوريتم رَنتيك بر طبقهبندى..

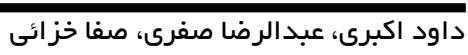

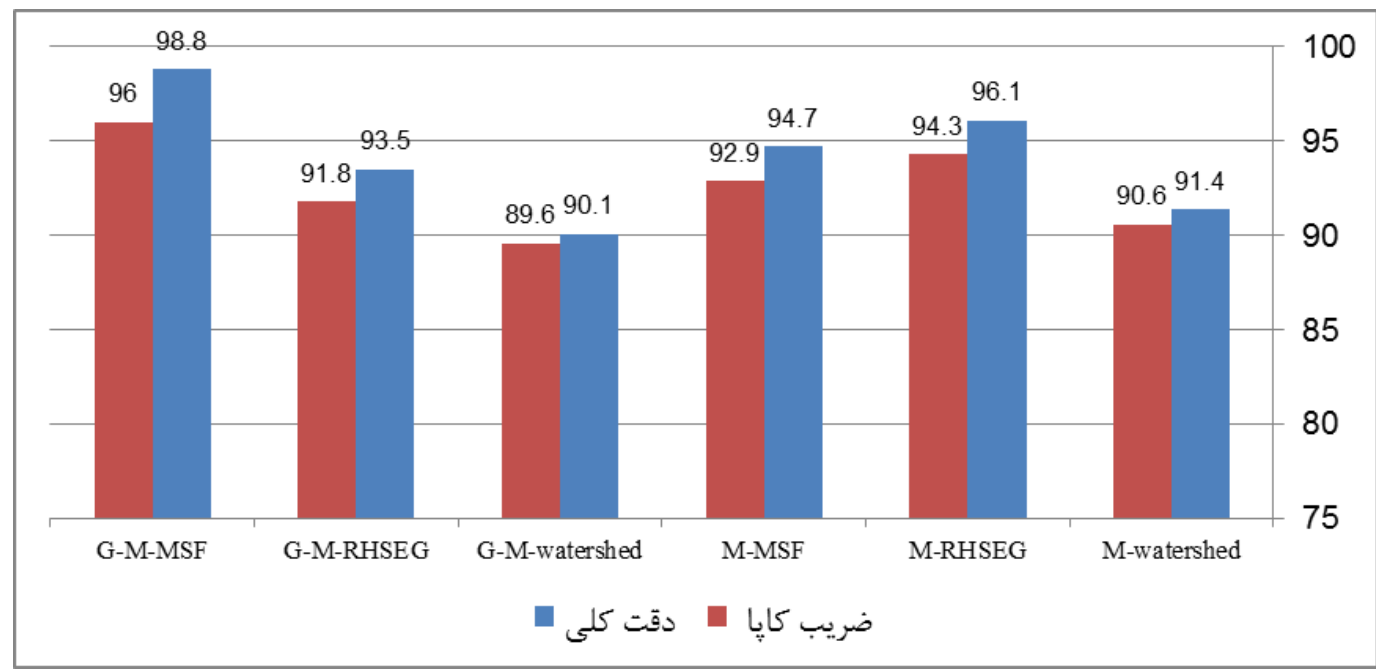

(الف)

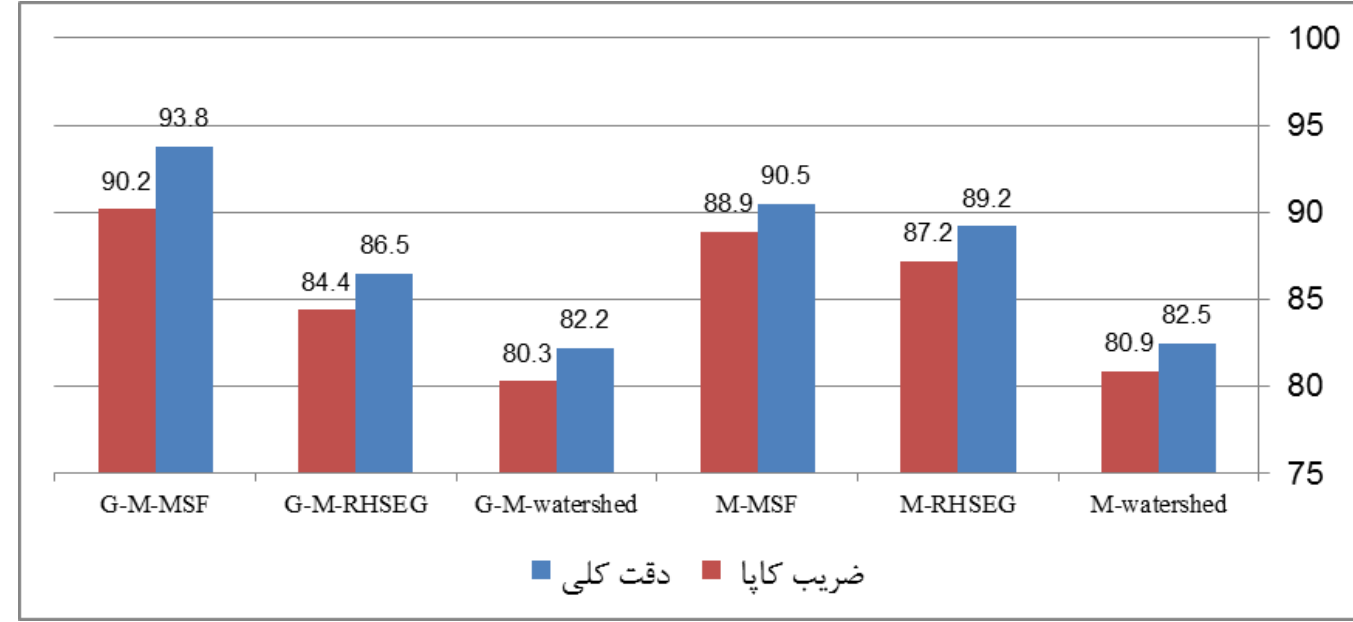

(ب)

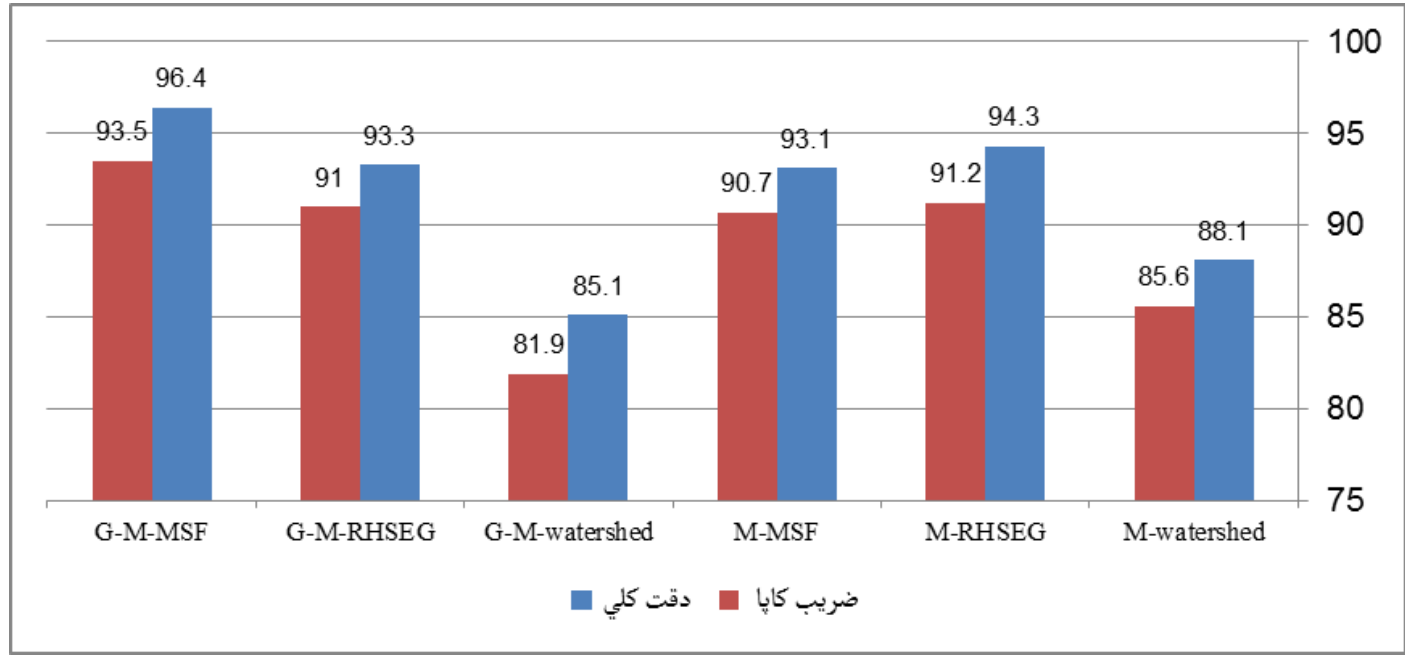

(ج)

شكل1: مقادير دقت كلى و ضريب كايا براى الكوريتمهاى طبقهبندى مختلف در تصوير (الف) Pavia، (ب) Telops و (ج) DC Mall 
دقت توليدكننده در هر سـهـ تصـوير، اكثـرا مربـوط بــه Pavia به جز كلاس شن و در تصوير DC Mall بــه جـز كلاس جمنزار، مابقى كلاسهــا داراى دقتـى بيشـتر از • 9 درصد هستند. جدول(9) مدت زمان اجراى الكوريتهمهاى طبقـهبنــى هـى مورد استفاده در اين تحقيق را نشان مى دهدي. همـانطور

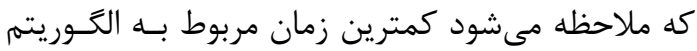

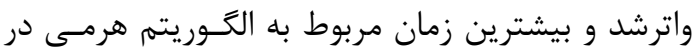
سه تصوير ابر طيفى مورد استفاده مسىباشـد. همجنــين

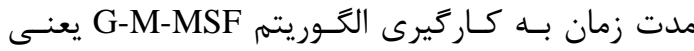

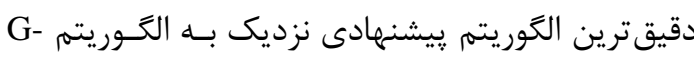

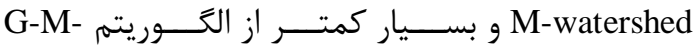
RHSEG الكوريتم G-M-MSF مىشود. به طورى كـه در تصـوير

به عبارت ديخــر الخـوريتهمهـاى واترشــد و هرمـى جـزءء روشهاى قطعهبندى مكانى بوده كه عمـل زـروهبنـدى

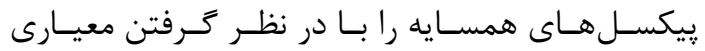
MSF مشخص انجام مى دهند. در حـالى كـهـ الخــوريتهم جزء الكَوريتمهاى قطعهبندى گر اف مبنـا مىباشد كه بــه باندهاى تصوير وابسته است و از اين رو كـاهش ابعـاد و حذف باندهاى نويزى مى تواند باعث افزايش دقـت ايـن

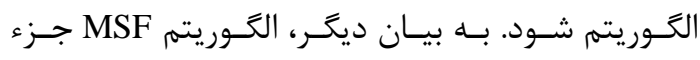

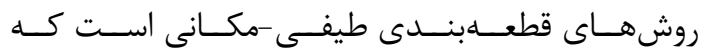
با در نظركرفتن اطلاعات طيفى و مكـانى ييكسـلهــا،

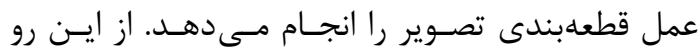
در اين الخوريتم نتايج حاصله متاثر از ويزگى هاى طيفى مورد استفاده بوده و با انتخاب ويززگى هاى طيفى بهينــه مى توان به نتايج بهترى دست يافت. همجنـين با توجـهـ

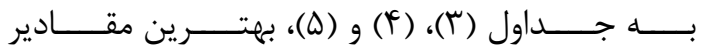
جدول \&: مدت زمان اجراى الكَوريتمهاى طبقهبندى مورد استفاده در سه تصوير ابرطيفى (اعداد برحسب ثانيه مىباشند.)

\begin{tabular}{|c|c|c|c|c|c|c|}
\hline $\begin{array}{l}\text { G-M- } \\
\text { MSF }\end{array}$ & $\begin{array}{r}\text { G-M- } \\
\text { RHSEG }\end{array}$ & $\begin{array}{r}\text { G-M- } \\
\text { watershed }\end{array}$ & $\begin{array}{r}\text { M- } \\
\text { MSF }\end{array}$ & $\begin{array}{r}\text { M- } \\
\text { RHSEG }\end{array}$ & $\begin{array}{r}\text { M- } \\
\text { watershed }\end{array}$ & تصاده \\
\hline$r \Delta l$ & $\Delta I T$ & זس" & 111 & $r \Delta \Delta$ & gf & Pavia \\
\hline TVI & $r \cdot \Lambda$ & rYA & $1 \cdot r$ & rtr & $\Delta \wedge$ & Telops \\
\hline 191 & rVT & $1 \Delta r$ & $\Lambda F$ & rGA & rq & DC Mall \\
\hline
\end{tabular}

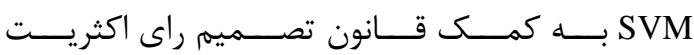
تركيب گرديـد. روش بيشــنهادى بـر روى سـهـ تصـوير

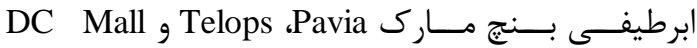

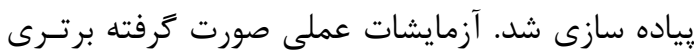

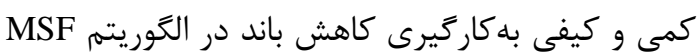

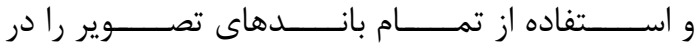

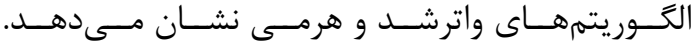

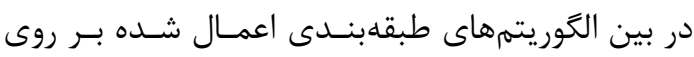
تمام باندهاى تصوير، الگوريتم هرمى در تصـاوير Pavia و DC Mall و الخـوريتم MSF در تصــوير Telops بــــ

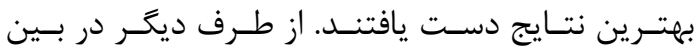
الكوريتمهاى اعمال شده بر روى باندهاى كاهش يافتـه،

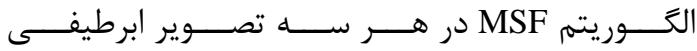

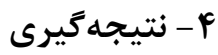

در اين تحقيق تاثير كـاهش ابعـاد بـهـ كمـك الخـوريتم زنتيك بر الگوريتمهاى طبقهبندى طيفى -مكانى تصاوير

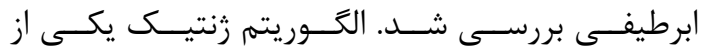
كارآمدترين و مـوثرترين الخـوريتمهــا در كـاهش ابعـاد

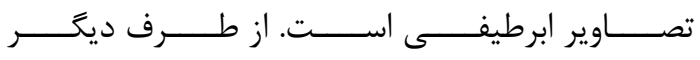
الخوريتمهاى قطعهبندى واترشد، هرمى و MSF مبتنىى بـر نشـانه مــورد اسـتفاده در ايـن تحقيـق نيـز جــزء دقيقترين الخوريتمهاى اسـتخراج اطلاعـات مكـانى در تصاوير ابرطيفى مىباشــند. در روش ريشــــهـادى بعـد از از انجام عمل قطعهبندى بر روى تصوير با باندهاى كاهش

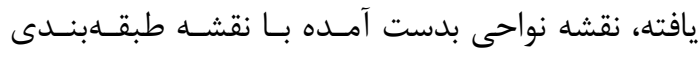


تاثير انتخاب ويزگَى به كمك الكَوريتم ثرنتيك بر طبقهبندى... داود اكبرى، عبدالرضا صفرى، صفا خزائى

ضريب كايا به ميـزان و، · ل و م درصـد در مقايسـه بـا

الخوريتم M-watershed و به ترتيب در تصـاوير Pavia،

Telops

[1] P. K. Varshney, and M. K. Arora, "Advanced Image Processing Techniques for Remotely Sensed Hyperspectral Data", Springer Berlin Heidelberg New York, 2004.

[2] R. C. Gonzalez, and R. E. Woods, "Digital Image Processing", Prentice Hall, 2002, 617 $-626$.

[3] S. Homayouni, and M. Roux, "Material Mapping from Hyperspectral Images using Spectral Matching in Urban Area", IEEE Workshop on Advances in Techniques for analysis of Remotely Sensed Data, NASA Goddard center, Washington DC, USA, 2003.

[4] C. I. Chang, Hyperspectral Imaging: Techniques for spectral Detection and Classification. Orlando, FL: Kluwer Academic, 2003.

[5] V. Vapnik, The Nature of Statistical Learning Theory. New York, NY: SpringerVerlag, 1995.

[6] Y. Tarabalka, J. Chanussot, and J. A. Benediktsson, "Segmentation and classification of hyperspectral images using minimum spanning forest grown from automatically selected markers", IEEE Trans. Syst., Man, Cybern. B, Cybern., vol. 40, pp. 1267-1279, 2010.

[7] J. A. Richards, and X. Jia, Remote Sensing Digital Image Analysis: An Introduction. Springer- Verlag Berlin Heidelberg, 2006.

[8] J. A. Richards, and X. Jia, Remote Sensing Digital Image Analysis: An Introduction. Springer- Verlag Berlin Heidelberg, 2006.

[9] X. Huang, and L. Zhang, "A comparative study of spatial approaches for urban mapping using hyperspectral rosis images over pavia city, northern Italy", International Journal of Remote Sensing, 30(12):3205-3221, 2009.

[10]J. A. Benediktsson, M. Pesaresi, and K. Arnason, "Classification and feature extraction for remote sensing images from urban areas based on morphological transformations", IEEE Trans. Geos. And

$$
\begin{aligned}
& \text { G-M- داراى بهترين نتايج مىباشد. همجنـين الخـوريتم } \\
& \text { MSF } \\
& \text { طبقهبندى مطرح شده داشته و باعـث افـزايش يــارامتر } \\
& \text { مراجع }
\end{aligned}
$$

Remote Sens., 41(9):1940-1949, 2003.

[11] M. Pesaresi, and J. A. Benediktsson, "A new approach for the morphological segmentation of high-resolution satellite imagery", IEEE Trans. Geosci. Remote Sens., vol. 39, no. 2, pp. 309-320, 2001.

[12] J. A. Benediktsson, J. A. Palmason, and J. R. Sveinsson, "Classification of hyperspectral data from urban areas based on extended morphological profiles", IEEE Trans. Geos. and Remote Sens., 43(3):480-491, 2005.

[13]Y. Tarabalka, J. C. Tilton, J. A. Benediktsson, and J. Chanussot, "A MarkerBased Approach for the Automated Selection of a Single Segmentation from a Hierarchical Set of Image Segmentations", IEEE Journal of Selected Topics in Applied Earth Observations and Remote Sensing, 2011.

[14] A. Bitam, and S. Ameur, "A local-spectral fuzzy segmentation for MSG multispectral images", International Journal of Remote Sensing, 34: 8360-8372, 2013.

[15] Y. Tarabalka, J. A. Benediktsson, and J. Chanussot, "Spectral-spatial classification of hyperspectral imagery based on partitional clustering techniques", IEEE Translation Geoscience Remote Sensing, 47(9): 29732987, 2009.

[16]Y. Tarabalka, J. A. Benediktsson, J. Chanussot, and J. C. Tilton, "Multiple spectral-spatial classification approach for hyperspectral data", IEEE Translation Geoscience Remote Sensing, 48(11): 41224132, 2010

[17]P. Soille, Morphological Image Analysis. 2nd ed. Berlin, Germany: Springer-Verlag, 2003.

[18]O. Gómez, J. A. González, and E. F. Morales, "Image segmentation using automatic seeded region growing and instance-based learning", in Proc. 12th Iberoamerican Congress Pattern Recognition, Valparaiso, Chile, 192-201, 2007.

[19]G. Noyel, "Filtrage, Réduction de 
Dimension, Classification et Segmentation Morphologique Hyperspectrale", Ph.D. dissertation, Ctr. Mathematical Morphology, Paris Sch. Mines, Paris, France, 2008.

[20] G. Noyel, J. Angulo, and D. Jeulin, "Morphological segmentation of hyperspectral images", Image Anal. Stereol., 26: 101-109, 2007.

[21]L. Zhuo, and J. Zheng, "A Genetic Algorithm Based Wrapper Feature Selection Method for Classification of Hyperspectral Image Using Support Vector Machine", The International Archives of the Photogrammetry, Remote Sensing and Spatial Information Sciences, 397-402, 2008.

[22]C.-L. Huang, and C.-J. Wang, "A GA-based feature selection and parameter optimization for support vector machines", Expert Systems with Application, 231-240, 2006.

[23] L. Vincent, and P. Soille, "Watersheds in digital spaces: an efficient algorithm based on immersion simulations", IEEE Translation Pattern Anal. Mach. Intell., 583598, 1991.

[24] J. Tilton, "Analysis of hierarchically related image segmentations", in Proc. IEEE Workshop Adv. Tech. Anal. Remotely Sensed Data, 60-69, 2003.

[25] J. Tilton, "RHSEG User's Manual: Including the Core RHSEG Open Source Release, HSEGExtract, HSEGReader and HSEGViewer", 2009.

[26]F. Van der Meer, "The effectiveness of spectral similarity measures for the analysis of hyperspectral imagery", Int. J. Appl. Earth Observation Geoinformation, vol. 8, no. 1, pp. 3-17, 2006.

[27]N. Cristianini, and J. Shawe-Taylor, "An Introduction to Support Vector Machines and Other Kernel-based Learning Methods", Cambridge University Press, 2000. 


\title{
The effect of feature selection using genetic algorithms on spectral- spatial classification of hyperspectral imagery
}

Davood Akbari ${ }^{1}$, Abdolreza Safari ${ }^{2}$, Safa Khazai $^{3}$

1- Remote Sensing PhD student, School of Surveying and Geospatial Engineering, University of Tehran

2- Associate Professor of Geodesy, School of Surveying and Geospatial Engineering, University of Tehran

3- Assistant Professor of Remote Sensing, Civil Engineering Department, Imam Hussein Comprehensive University

\begin{abstract}
Hyperspectral remote sensing technologies have many applications in land cover classification and study their changes. With recent developments and create images with high spatial resolution, it is necessary the use of both spatial and spectral information in hyperspectral image classification. In this paper, we have evaluated the effect of dimensionality reduction using genetic algorithm on spectral-spatial classification of hyperspectral imagery. So far, among the various algorithms spectral-spatial classification of hyperspectral images, three segmentation algorithms, watershed, hierarchical and Minimum Spanning Forest (MSF) based on markers, combined with Support Vector Machines (SVM) to achieve the best results. In the proposed approach, the dimension of hyperspectral images is first reduced by using genetic algorithm. Then, the three mentioned segmentation algorithms are applied on the resulting bands. Finally, the obtained segmentation maps are combined with SVM classification map using majority voting rule. The proposed approach was implemented on three hyperspectral data sets, the Pavia dataset, the Telops dataset, and the DC Mall dataset. The obtained experimental results indicate the superiority use of reduced bands in MSF based on markers algorithm and all bands in watershed and hierarchical based on markers algorithms.
\end{abstract}

Key words: Hyperspectral image, Spectral-Spatial Classification, Dimensionality reduction, Genetic algorithm.

Correspondence Address: No. 53, Modarres 23, Modarres St., Birjand, South Khorasan, Iran. Email: davoodakbari@ut.ac.ir 